\title{
Kinetic Rates for Gas-Phase Chemistry of Phenolic-Based Carbon Ablator in Atmospheric Air
}

\author{
Alexandre Martin* \\ University of Kentucky, Lexington, Kentucky 40506 \\ Ioana Cozmuta ${ }^{ \pm}$and Michael J. Wright $\stackrel{ \pm}{ \pm}$ \\ NASA Ames Research Center, Moffett Field, California 94035 \\ and \\ Iain D. Boyd폴 \\ University of Michigan, Ann Arbor, Michigan 48109 \\ DOI: $10.2514 / 1 . T 4184$
}

\begin{abstract}
A comparison between three chemistry models used for the aerothermodynamic modeling of carbon-based phenolic ablative heat shields in atmospheric air is presented. The differences between the models, as well as the results they produced for the boundary-layer composition and prediction of convective and radiative heat fluxes, are put forward. A new model, built by optimizing and reducing a baseline model constructed using kinetic rates from a combustion database, is presented. Some of the important reactions, such as the $\mathrm{CN} / \mathrm{CO}$ exchange, are highlighted, and their effects on surface heating are discussed. The resulting model comprises an extensive set of reactions that are relevant to carbon-phenolic ablators in high-enthalpy re-entry environments. The analysis presented in this paper shows that this model preserves the important features of the three existing chemistry models while correcting their deficiencies for a more accurate description pertinent to re-entry conditions.
\end{abstract}

\section{Nomenclature}

$A=$ preexponent factor; mol, $\mathrm{cm}, \mathrm{s}$

$B_{c}^{\prime}=$ nondimensional surface ablation rate

$B_{g}^{\prime}=$ nondimensional pyrolysis gas rate

C $=$ vector of source terms

$D=$ mass diffusion coefficient, $\mathrm{m}^{2} / \mathrm{s}$

$E \quad=$ energy, $\mathrm{J} / \mathrm{m}^{3}$

$\boldsymbol{F} \quad=$ inviscid flux matrix

$\boldsymbol{F}_{d} \quad=$ diffusive flux matrix

$\boldsymbol{h}=$ species enthalpy vector, $\mathrm{J} / \mathrm{kg}$

$I \quad=$ identity matrix

$\boldsymbol{J} \quad=$ directional species diffusion, $\mathrm{kg} /\left(\mathrm{m}^{2} \cdot \mathrm{s}\right)$

$k=$ kinetic rate; mole, $\mathrm{cm}, \mathrm{s}$

$\dot{m}^{\prime \prime} \quad=$ mass rate, $\mathrm{kg} /\left(\mathrm{m}^{2} \cdot \mathrm{s}\right)$

$n=$ preexponent temperature power

$p=$ pressure, $\mathrm{Pa}$

$\boldsymbol{Q} \quad=\quad$ vector of conserved variables

$q \quad=$ heat flux, $\mathrm{W} / \mathrm{m}^{2}$

$S \quad=$ nondimensional sensitivity

$T=$ temperature, $\mathrm{K}$

$T_{a} \quad=\quad$ activation temperature, $\mathrm{K}$

$t \quad=$ time, $\mathrm{s}$

$U, \boldsymbol{u}, v=$ velocity, $\mathrm{m} / \mathrm{s}$

$\dot{\boldsymbol{w}}=$ mass source term, $\mathrm{kg} /\left(\mathrm{m}^{3} \mathrm{~s}\right)$

$\dot{w}_{v} \quad=$ Vibrational energy relaxation source term, $\mathrm{J} /\left(\mathrm{m}^{3} \mathrm{~s}\right)$

Presented as Paper 2010-1175 at the 48th AIAA Aerospace Sciences Meeting and Exhibit, Orlando, FL, 4-7 January 2010; received 7 May 2013; revision received 15 September 2014; accepted for publication 16 September 2014; published online 8 January 2015. Copyright (C) 2014 by the authors. Published by the American Institute of Aeronautics and Astronautics, Inc., with permission. Copies of this paper may be made for personal or internal use, on condition that the copier pay the $\$ 10.00$ per-copy fee to the Copyright Clearance Center, Inc., 222 Rosewood Drive, Danvers, MA 01923; include the code 1533-6808/15 and $\$ 10.00$ in correspondence with the CCC.

*Assistant Professor, Department of Mechanical Engineering, 261 Ralph G. Anderson Building; Associate Faculty at the Center for Computational Science. Associate Fellow AIAA.

'Senior Research Scientist, Space Portal, Science and Technology Corporation. Member AIAA.

¥Manager, Entry Systems Modeling Project, Entry Systems and Technology Division. Associate Fellow AIAA.

${ }^{\S}$ James E. Knott Professor of Engineering, Department of Aerospace Engineering, 3000 Francois-Xavier Bagnoud Building. Fellow AIAA.

$\begin{array}{ll}X & =\text { sensitive variable } \\ x & =\text { coordinate, } \mathrm{m} \\ Y & =\text { mass fraction, } \mathrm{kg} / \mathrm{kg} \\ \eta & =\text { distance normal to the wall, } \mathrm{m} \\ \rho & =\text { density, } \mathrm{kg} / \mathrm{m}^{3} \\ \tau & =\text { viscous tensor, } \mathrm{Pa}\end{array}$

Subscripts

$\begin{array}{ll}g & =\text { gas blown } \\ \mathrm{nc} & =\text { next to the wall } \\ s & =\text { species } \\ \mathrm{tr} & =\text { translational rotational } \\ \mathrm{ve} & =\text { vibrational-electron-electronic excitation } \\ w & =\text { wall } \\ \infty & =\text { free stream }\end{array}$

\section{Introduction}

$\mathbf{T}$ HE thermal protection system (TPS) of a vehicle entering a planetary atmosphere is one of the key components of its design. The main role of the TPS is to protect the structural integrity of the spacecraft against extreme heating. A wide variety of TPS materials exist, and they can usually be classified into two main categories: ablative materials, such as PICA (used on missions such as Stardust, Mars Science Laboratory, and Space-X Dragon) and non-ablative materials, such as ceramic tiles (used on the space shuttles).

Both materials manage impinging heating in two ways: via reradiation (usually about $90 \%$ of the total heat flux) and conduction. What distinguishes them is that ablators protect against higher heating exposure due to two additional mechanisms: pyrolysis and ablation. Upon heating, the conduction energy transferred to the material induces a change in its chemical state by triggering exothermic chemical reactions characteristic to thermal decomposition. The generated gases travel to the surface and are blown into the boundary layer, changing its chemical composition. The details of these interactions are highly complex and necessitate tightly coupled models to accurately capture them $[1,2]$.

Current aerothermodynamic, computational fluid dynamics (CFD) codes use chemistry models to account for the chemical species in the flow field, as well as for the effects of the pyrolysis gases. Because ablation coupling is becoming an increasingly important research 
topic [3-9], the development of an accurate yet computationally efficient and usable chemistry model is of great importance. The models proposed and used so far [10-12] have been known to omit important reactions and use outdated or incorrect reaction rates. Moreover, some of the assumptions made for past chemistry models might not be appropriate for used in modern, higher-fidelity hypersonic CFD codes.

The first part of this paper takes a closer look at three previously published chemistry models by testing them in a hypersonic CFD code. Using a representative but extreme test case, they are evaluated by taking a closer look at the boundary-layer composition as well as the convective and radiative heat fluxes. The discrepancy between the results clearly shows the need to develop a more comprehensive chemistry model, which would still run efficiently in a CFD code. The second part of the paper presents such a model. The elaboration of the model is performed following the methodology proposed by Ref. [13]. First, an extensive baseline model is assembled using as many chemical reactions and species as reasonably possible, regardless of their apparent importance. The number of species and reactions is then reduced by performing a sensitivity analysis over key parameters such as temperature and the mole fraction of important species. The new model consists of 55 species and 158 reactions, which is reasonable enough to be used efficiently in hypersonic CFD codes, such as the ones presented in Refs. [14-17].

\section{LeMANS: An Unstructured Three-Dimensional Navier-Stokes Solver for Hypersonic Non-Equilibrium Aerothermodynamics}

The aerothermodynamic CFD code used in this analysis is LeMANS, which is a finite volume Navier-Stokes solver [14]. The code assumes that the rotational and translational energy modes of all species are described by the temperature $T_{\text {tr }}$ and that the vibrational energy mode of all species and the electronic energy can be described by a single temperature $T_{\mathrm{ve}}$ [18]. The latter is computed using the species vibrational energy modeled as a harmonic oscillator. The viscous stresses are modeled assuming a Newtonian fluid and using Stokes's hypothesis. The species mass diffusion fluxes are modeled using a modified version of Fick's law, which ensures that the sum of all the species diffusion velocity is zero. Mixture transport properties are calculated using Wilke's semi-empirical mixing rule [19], with species viscosities calculated using Blottner's model [20] and species thermal conductivities determined using Eucken's relation [21]. Heat fluxes are modeled for all temperatures according to Fourier's law. Finally, the source terms of the species conservation equations are modeled using a standard finite-rate chemistry model for reacting air in conjunction with Park's two-temperature model [22] in order to account for thermal non-equilibrium effects on the reaction rates.

The governing equations for the code can be written under the following form:

$$
\frac{\partial \boldsymbol{Q}}{\partial t}+\nabla \cdot\left(\boldsymbol{F}-\boldsymbol{F}_{d}\right)=\boldsymbol{C}
$$

where

$$
\boldsymbol{Q}=\left(\begin{array}{c}
\rho \boldsymbol{Y}^{T} \\
\rho \boldsymbol{u}^{T} \\
E \\
E_{\mathrm{ve}}
\end{array}\right) \quad \text { and } \quad \boldsymbol{C}=\left(\begin{array}{c}
\dot{w}^{T} \\
\mathbf{0}^{T} \\
0 \\
\dot{w}_{v}
\end{array}\right)
$$

are the vector of conserved variables and the vector of source terms, respectively. In these equations, $\boldsymbol{Y}=\left(Y_{1}, \ldots, Y_{n s}\right)$ is the species densities vector, $\boldsymbol{u}$ are the bulk velocity components, and $E$ and $E_{\mathrm{ve}}$ are the total and the vibrational-electron-electronic excitation energy per unit volume of mixture.
The inviscid and diffusive flux matrices are given by

$$
\boldsymbol{F}=\left(\begin{array}{c}
\rho \boldsymbol{Y}^{T} \boldsymbol{u} \\
\rho \boldsymbol{u}^{T} \boldsymbol{u}+\boldsymbol{I} p \\
(E+p) \boldsymbol{u} \\
E_{\mathrm{ve}} \boldsymbol{u}
\end{array}\right) \quad \text { and } \quad \boldsymbol{F}_{d}=\left(\begin{array}{c}
-\boldsymbol{J} \\
\boldsymbol{\tau} \\
\boldsymbol{u} \boldsymbol{\tau}-\left(\boldsymbol{q}_{\mathrm{tr}}+\boldsymbol{q}_{\mathrm{ve}}\right)-\left(\boldsymbol{h}^{T} \boldsymbol{J}\right) \\
-\boldsymbol{q}_{\mathrm{ve}}-\left(\boldsymbol{e}_{\mathrm{ve}}^{T} \boldsymbol{J}\right)
\end{array}\right)
$$

where $p$ is the pressure; $\boldsymbol{\tau}$ is the viscous tensor; and $\boldsymbol{q}_{\mathrm{tr}}$ and $\boldsymbol{q}_{\mathrm{ve}}$ are, respectively, the directional translational-rotational and vibrationalelectron-electronic excitation heat flux vectors. Moreover, $\boldsymbol{h}$ is the species enthalpy vector, and $\boldsymbol{J}$ is the directional species diffusion flux tensor. The details of these equations and models are found in Ref. [23].

Numerically, the code has the capability to handle meshes containing any mix of hexahedra, tetrahedra, prisms, and pyramids in three dimensions, or triangles and quadrilaterals in two dimensions. Numerical fluxes between the cells are discretized using a modified Steger-Warming flux vector splitting [24], which has low dissipation and is appropriate to calculate boundary layers. A point or line implicit method is used to perform the time integration.

The code has been extensively compared with laboratory data, such as the Apollo experimental model [23], the Mars Entry Spacecraft model $[23,25]$, the Calspan blunted cone experimental model [26], and the Mars Science Laboratory model [27-29]; as well as flight data such as the RAM-C II spacecraft [23,30], the IRV-2 vehicle [1], and the FIRE-II spacecraft [31]. It has also been compared [31] to similar codes, such as DPLR [16] and LAURA [17], and used to predictively model many spacecraft, such as the Stardust return capsule $[30,32,33]$ and the Automatic Transport Vehicle "JulesVerne" [3] .

To account for the coupling between the flow field and the material response, ablation is added to the CFD code by modifying the surface boundary condition [1]. The dependent variables at the wall are obtained by solving the momentum balance equation:

$$
p_{\mathrm{nc}}+\rho_{\mathrm{nc}} v_{\mathrm{nc}}^{2}=p_{w}\left(\rho_{w}, T_{w}\right)+\rho_{w} v_{w}^{2}
$$

as well as the species surface mass balance equation:

$$
\rho_{w} D_{w s} \frac{\partial Y_{w s}}{\partial \eta}=\dot{m}^{\prime \prime}\left(Y_{g s}-Y_{w s}\right)
$$

The present work imposes wall temperature, blowing rates, and blowing species at the boundary, since it is not dynamically coupled to a material response code.

Once values are computed for the primitive variables, the conservative quantities in the ghost cells of the boundary are set such that the flux across the wall is the required blowing flux. This blowing boundary condition has been tested over a wide range of blowing rates, which assures the robustness of the implementation. Following the same methodology for the verification and validation of DPLR [35] and LAURA [36], the blowing boundary of LeMANS has also been verified and validated $[\underline{1}, \underline{9}, \underline{37}]$.

\section{A. Model Description}

Three kinetic models for air and carbon phenolic chemistry have been identified in the available literature. In the following subsections, each model is tested in the CFD code LeMANS using a representative re-entry problem. To single out the effects of kinetic rates, all of the models use identical thermodynamic data (CEA database [38]) and transport properties.

1. Park's 20-Species Model

The first model used in the present comparison was developed by Park et al. in 2000 [10]. It uses 20 species and is largely based on the 11-species air model combined with parts of a reaction mechanism 
used for Mars entry. The model includes 23 reactions, five of which are dissociations reactions, and is numerically fast.

It has been shown, however, that for certain re-entry conditions and types of TPS materials, species such as $\mathrm{O}_{2}^{+}$and $\mathrm{HCN}$ are important energy carriers $[11,22]$ and should be included. Also, certain key reactions such as $\overline{\mathrm{NO}}$ and $\mathrm{C}_{3}$ dissociation, which provide paths to the reduction of large molecules, are not included. The model also offers a complete and comprehensive set of data including collisional cross sections, surface reactions, and equilibrium constant curve fits. The 23 reactions of this model have been gathered from Refs. [10,22,3942], and are listed in Table $\underline{1}$. The 20 species are

$$
\begin{gathered}
\mathrm{C}, \mathrm{O}, \mathrm{N}, \mathrm{H}, \mathrm{CO}, \mathrm{C}_{2}, \mathrm{~N}_{2}, \mathrm{CN}, \mathrm{NO}, \mathrm{O}_{2}, \mathrm{H}_{2}, \mathrm{C}_{3}, \\
\mathrm{C}_{2} \mathrm{H}, \mathrm{C}^{+}, \mathrm{O}^{+}, \mathrm{H}^{+}, \mathrm{N}^{+}, \mathrm{NO}^{+}, \mathrm{N}_{2}^{+}, \mathrm{e}^{-}
\end{gathered}
$$

\section{Suzuki's 26 Species Model}

The second model studied here was created for the preflight analysis of the MUSES-C (now called Hayabusa) re-entry vehicle [11] and uses 26 species and 50 reactions (12 dissociations). A key issue with this model is that it is mainly based on rates that date from the late 1960s to the late 1980s [43-47]. It also lacks certain species that might be important at some flight conditions of high-speed carbon-phenolic TPS entries, such as $\mathrm{H}^{+}$, as noted in Ref. [10] and shown in Ref. [48]. The reactions of this model have been gathered from Refs. [43-47], and are listed in Table $\underline{2}$. The species are

$$
\begin{gathered}
\mathrm{C}, \mathrm{O}, \mathrm{N}, \mathrm{H}, \mathrm{CO}, \mathrm{C}_{2}, \mathrm{~N}_{2}, \mathrm{CH}, \mathrm{CN}, \mathrm{NO}, \mathrm{O}_{2}, \mathrm{H}_{2}, \mathrm{CO}_{2}, \mathrm{C}_{3} \mathrm{C}_{2} \mathrm{H} \\
\mathrm{HCN}, \mathrm{HCO}, \mathrm{C}_{2} \mathrm{H}_{2}, \mathrm{C}^{+}, \mathrm{O}^{+}, \mathrm{NO}^{+}, \mathrm{N}_{2}^{+}, \mathrm{CO}^{+}, \mathrm{O}_{2}^{+}, \mathrm{e}^{-}
\end{gathered}
$$

\section{Olynick's 18 Species Model}

The third model studied here was created for the preflight analysis of the Stardust re-entry vehicle [12] and uses 18 species and 22 reactions ( 9 dissociations). This model was build for efficiency, and therefore lacks important air species (the ionized diatomic molecules). The reaction rates used for the impact ionization reactions [49] are also outdated, as are some of the carbon chemistry rates. The other drawback is that the model lacks almost any hydrocarbon chemistry, with only two equations involving the element $\mathrm{H}$. Finally, most of the rates that have carbon species are taken from a model built and

\begin{tabular}{|c|c|c|}
\hline No. & Reactions & References \\
\hline 1 & $\mathrm{~N}_{2}+\mathrm{M} \rightleftharpoons 2 \mathrm{~N}+\mathrm{M}$ & [22] \\
\hline 2 & $\mathrm{O}_{2}+\mathrm{M} \rightleftharpoons 2 \mathrm{O}+\mathrm{M}$ & {$[\overline{22}]$} \\
\hline 3 & $\mathrm{C}_{2}+\mathrm{M} \rightleftharpoons 2 \mathrm{C}+\mathrm{M}$ & [39] \\
\hline 4 & $\mathrm{CN}+\mathrm{M} \rightleftharpoons \mathrm{C}+\mathrm{N}+\mathrm{M}$ & [39] \\
\hline 5 & $\mathrm{H}_{2}+\mathrm{M} \rightleftharpoons 2 \mathrm{H}+\mathrm{M}$ & [40] \\
\hline 6 & $\mathrm{~N}+\mathrm{e}^{-} \rightleftharpoons \mathrm{N}^{+}+\mathrm{e}^{-}+\mathrm{e}^{-}$ & {$[\overline{22}]$} \\
\hline 7 & $\mathrm{O}+\mathrm{e}^{-} \rightleftharpoons \mathrm{O}^{+}+\mathrm{e}^{-}+\mathrm{e}^{-}$ & {$[\overline{22}]$} \\
\hline 8 & $\mathrm{C}+\mathrm{e}^{-} \rightleftharpoons \mathrm{C}^{+}+\mathrm{e}^{-}+\mathrm{e}^{-}$ & [10] \\
\hline 9 & $\mathrm{H}+\mathrm{e}^{-} \rightleftharpoons \mathrm{H}^{+}+\mathrm{e}^{-}+\mathrm{e}^{-}$ & [10] \\
\hline 10 & $\mathrm{~N}_{2}+\mathrm{O} \rightleftharpoons \mathrm{NO}+\mathrm{N}$ & [41] \\
\hline 11 & $\mathrm{NO}+\mathrm{O} \rightleftharpoons \mathrm{O}_{2}+\mathrm{N}$ & {$[\overline{42}]$} \\
\hline 12 & $\mathrm{CO}+\mathrm{C} \rightleftharpoons \mathrm{C}_{2}+\mathrm{O}$ & 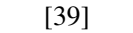 \\
\hline 13 & $\mathrm{CO}+\mathrm{O} \rightleftharpoons \mathrm{O}_{2}+\mathrm{C}$ & [39] \\
\hline 14 & $\mathrm{CO}+\mathrm{N} \rightleftharpoons \mathrm{CN}+\mathrm{O}$ & [39] \\
\hline 15 & $\mathrm{~N}_{2}+\mathrm{C} \rightleftharpoons \mathrm{CN}+\mathrm{N}$ & [39] \\
\hline 16 & $\mathrm{CN}+\mathrm{O} \rightleftharpoons \mathrm{NO}+\mathrm{C}$ & [39] \\
\hline 17 & $\mathrm{CN}+\mathrm{C} \rightleftharpoons \mathrm{C}_{2}+\mathrm{N}$ & [39] \\
\hline 18 & $\mathrm{CO}+\mathrm{C}_{2} \rightleftharpoons \mathrm{C}_{3}+\mathrm{O}$ & [10] \\
\hline 19 & $\mathrm{C}_{3}+\mathrm{N} \rightleftharpoons \mathrm{CN}+\mathrm{C}_{2}$ & [10] \\
\hline 20 & $\mathrm{C}_{3}+\mathrm{C} \rightleftharpoons \mathrm{C}_{2}+\mathrm{C}_{2}$ & [10] \\
\hline 21 & $\mathrm{C}_{2} \mathrm{H}+\mathrm{H} \rightleftharpoons \mathrm{C}_{2}+\mathrm{H}_{2}$ & [10] \\
\hline 22 & $\mathrm{O}+\mathrm{N} \rightleftharpoons \mathrm{NO}^{+}+\mathrm{e}^{-}$ & {$[\overline{22}]$} \\
\hline 23 & $\mathrm{~N}+\mathrm{N} \rightleftharpoons \mathrm{N}_{2}^{+}+\mathrm{e}^{-}$ & [22] \\
\hline
\end{tabular}
validated for the atmospheric conditions of Mars [39], which does not

Table 1 Forward reaction rates for Park et al.'s [10] 20-species chemistry model

\begin{tabular}{|c|c|c|}
\hline No. & Reactions & References \\
\hline 1 & $\mathrm{O}_{2}+\mathrm{M} \rightleftharpoons 2 \mathrm{O}+\mathrm{M}$ & [43] \\
\hline 2 & $\mathrm{~N}_{2}+\mathrm{M} \rightleftharpoons 2 \mathrm{~N}+\mathrm{M}$ & ["43] \\
\hline 3 & $\mathrm{NO}+\mathrm{M} \rightleftharpoons \mathrm{N}+\mathrm{O}+\mathrm{M}$ & [43] \\
\hline 4 & $\mathrm{NO}+\mathrm{O} \rightleftharpoons \mathrm{O}_{2}+\mathrm{N}$ & [43] \\
\hline 5 & $\mathrm{~N}_{2}+\mathrm{O} \rightleftharpoons \mathrm{NO}+\mathrm{N}$ & [43] \\
\hline 6 & $\mathrm{~N}+\mathrm{O} \rightleftharpoons \mathrm{NO}^{+}+\mathrm{e}^{-}$ & [43] \\
\hline 7 & $\mathrm{O}+\mathrm{O} \rightleftharpoons \mathrm{O}_{2}^{+}+\mathrm{e}^{-}$ & [프] \\
\hline 8 & $\mathrm{O}+\mathrm{O}_{2}^{+} \rightleftharpoons \mathrm{O}_{2}+\mathrm{O}^{+}$ & ["43] \\
\hline 9 & $\mathrm{~N}_{2}+\mathrm{N}^{+} \rightleftharpoons \mathrm{N}+\mathrm{N}^{+}$ & {$[\underline{43}]$} \\
\hline 10 & $\mathrm{~N}+\mathrm{N} \rightleftharpoons \mathrm{N}_{2}^{+}+\mathrm{e}^{-}$ & [프] \\
\hline 11 & $\mathrm{O}_{2}+\mathrm{N}_{2} \rightleftharpoons \mathrm{NO}+\mathrm{NO}^{+}+\mathrm{e}^{-}$ & [43] $]$ \\
\hline 12 & $\mathrm{NO}+\mathrm{M} \rightleftharpoons \mathrm{NO}^{+}+\mathrm{e}^{-}+\mathrm{M}$ & [43] \\
\hline 13 & $\mathrm{O}+\mathrm{NO}^{+} \rightleftharpoons \mathrm{NO}+\mathrm{O}^{+}$ & [43] \\
\hline 14 & $\mathrm{~N}_{2}+\mathrm{O}^{+} \rightleftharpoons \mathrm{O}+\mathrm{N}_{2}^{+}$ & [43] \\
\hline 15 & $\mathrm{~N}+\mathrm{NO}^{+} \rightleftharpoons \mathrm{NO}+\mathrm{O}^{+}$ & [43] \\
\hline 16 & $\mathrm{O}_{2}+\mathrm{NO}^{+} \rightleftharpoons \mathrm{NO}+\mathrm{O}_{2}^{+}$ & [프] \\
\hline 17 & $\mathrm{O}+\mathrm{NO}^{+} \rightleftharpoons \mathrm{O}_{2}+\mathrm{N}^{+}$ & {$[\underline{43}]$} \\
\hline 18 & $\mathrm{~N}+\mathrm{e}^{-} \rightleftharpoons \mathrm{N}^{+}+\mathrm{e}^{-}+\mathrm{e}^{-}$ & [43] \\
\hline 19 & $\mathrm{O}+\mathrm{e}^{-} \rightleftharpoons \mathrm{O}^{+}+\mathrm{e}^{-}+\mathrm{e}^{-}$ & ["43] \\
\hline 20 & $\mathrm{CO}_{2}+\mathrm{M} \rightleftharpoons \mathrm{CO}+\mathrm{O}+\mathrm{M}$ & [44] \\
\hline 21 & $\mathrm{CO}+\mathrm{M} \rightleftharpoons \mathrm{C}+\mathrm{O}+\mathrm{M}$ & [44] \\
\hline 22 & $\mathrm{C}_{2}+\mathrm{M} \rightleftharpoons 2 \mathrm{C}+\mathrm{M}$ & [45] \\
\hline 23 & $\mathrm{C}_{3}+\mathrm{M} \rightleftharpoons \mathrm{C}+\mathrm{C}_{2}+\mathrm{M}$ & 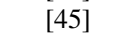 \\
\hline 24 & $\mathrm{CN}+\mathrm{M} \rightleftharpoons \mathrm{C}+\mathrm{N}+\mathrm{M}$ & [45] \\
\hline 25 & $\mathrm{~N}_{2}+\mathrm{C} \rightleftharpoons \mathrm{CN}+\mathrm{N}$ & 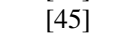 \\
\hline 26 & $\mathrm{CO}+\mathrm{N} \rightleftharpoons \mathrm{CN}+\mathrm{O}$ & 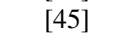 \\
\hline 27 & $\mathrm{CO}_{2}+\mathrm{N} \rightleftharpoons \mathrm{CN}+\mathrm{O}$ & {$[\overline{45}]$} \\
\hline 28 & $\mathrm{~N}_{2}+\mathrm{CO} \rightleftharpoons \mathrm{CN}+\mathrm{O}_{2}$ & [45] \\
\hline 29 & $\mathrm{CO}+\mathrm{NO} \rightleftharpoons \mathrm{CO}_{2}+\mathrm{N}$ & {$[\overline{45}]$} \\
\hline 30 & $\mathrm{CO}_{2}+\mathrm{O} \rightleftharpoons \mathrm{CO}+\mathrm{O}_{2}$ & [45] \\
\hline 31 & $\mathrm{CO}+\mathrm{CO} \rightleftharpoons \mathrm{CO}_{2}+\mathrm{C}$ & {$[\underline{45}]$} \\
\hline 32 & $\mathrm{CO}+\mathrm{O} \rightleftharpoons \mathrm{O}_{2}+\mathrm{C}$ & 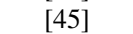 \\
\hline 33 & $\mathrm{CO}+\mathrm{N} \rightleftharpoons \mathrm{C}+\mathrm{NO}$ & [45] \\
\hline 34 & $\mathrm{CN}+\mathrm{O} \rightleftharpoons \mathrm{C}+\mathrm{NO}$ & [45] \\
\hline 35 & $\mathrm{CO}+\mathrm{CO} \rightleftharpoons \mathrm{C}_{2}+\mathrm{O}_{2}$ & {$[\overline{45}]$} \\
\hline 36 & $\mathrm{CO}+\mathrm{C} \rightleftharpoons \mathrm{C}_{2}+\mathrm{O}$ & [45] \\
\hline 37 & $\mathrm{C}_{2}+\mathrm{CO} \rightleftharpoons \mathrm{C}_{3}+\mathrm{O}$ & [프] \\
\hline 38 & $\mathrm{C}_{3}+\mathrm{C} \rightleftharpoons \mathrm{C}_{2}+\mathrm{C}_{2}$ & 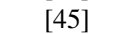 \\
\hline 39 & $\mathrm{CN}+\mathrm{H}_{2} \rightleftharpoons \mathrm{HCN}+\mathrm{H}$ & [46] \\
\hline 40 & $\mathrm{H}_{2}+\mathrm{M} \rightleftharpoons 2 \mathrm{H}+\mathrm{M}$ & ["ㄱ] \\
\hline 41 & $\mathrm{HCO}+\mathrm{M} \rightleftharpoons \mathrm{H}+\mathrm{CO}+\mathrm{M}$ & 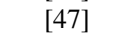 \\
\hline 42 & $\mathrm{HCO}+\mathrm{H} \rightleftharpoons \mathrm{CO}+\mathrm{H}_{2}$ & [47] \\
\hline 43 & $\mathrm{C}_{2} \mathrm{H}_{2}+\mathrm{M} \rightleftharpoons \mathrm{C}_{2} \mathrm{H}+\mathrm{H}+\mathrm{M}$ & [47] \\
\hline 44 & $\mathrm{C}_{2} \mathrm{H}_{2}+\mathrm{H} \rightleftharpoons \mathrm{C}_{2} \mathrm{H}+\mathrm{H}_{2}$ & [47] \\
\hline 45 & $\mathrm{C}_{2} \mathrm{H}_{2}+\mathrm{O}_{2} \rightleftharpoons \mathrm{HCO}+\mathrm{HCO}$ & [47] \\
\hline 46 & $\mathrm{C}_{2} \mathrm{H}+\mathrm{O}_{2} \rightleftharpoons \mathrm{HCO}+\mathrm{CO}$ & [47] \\
\hline 47 & $\mathrm{C}_{2} \mathrm{H}+\mathrm{O} \rightleftharpoons \mathrm{CH}+\mathrm{CO}$ & 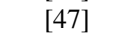 \\
\hline 48 & $\mathrm{CH}+\mathrm{O}_{2} \rightleftharpoons \mathrm{HCO}+\mathrm{O}$ & [47] \\
\hline 49 & $\mathrm{C}+\mathrm{O} \rightleftharpoons \mathrm{CO}^{+}+\mathrm{e}^{-}$ & [47] \\
\hline 50 & $\mathrm{C}+\mathrm{e}^{-} \rightleftharpoons \mathrm{C}^{+}+\mathrm{e}^{-}+\mathrm{e}^{-}$ & [47] \\
\hline
\end{tabular}

Table 2 Forward reaction rates for Suzuki et al.'s [11] 26-species chemistry model

have the same temperature ranges as carbon-phenolic-in-air surface ablation models. The reactions of this model have been gathered from Refs. $[\underline{39}, \underline{46}, \underline{49}-\underline{51}]$, and are listed in Table $\underline{3}$. The species are

$$
\begin{gathered}
\mathrm{C}, \mathrm{O}, \mathrm{N}, \mathrm{H}, \mathrm{CO}, \mathrm{C}_{2}, \mathrm{~N}_{2}, \mathrm{CN}, \mathrm{NO}, \mathrm{O}_{2}, \mathrm{H}_{2}, \\
\mathrm{CO}_{2}, \mathrm{C}_{3}, \mathrm{HCN}, \mathrm{C}^{+}, \mathrm{O}^{+}, \mathrm{N}^{+}, \mathrm{e}^{-}
\end{gathered}
$$

\section{B. Model Comparison: Species Composition}

In this section, a simple test case is used to evaluate each of these models in their published form, even if they might not have been designed for those exact conditions. The CFD test case uses the geometry of the forebody of the Stardust return capsule and uses the flight conditions at $48 \mathrm{~s}$ into re-entry (a few seconds before peak heating) [52]. This test case is chosen because uncoupled ablation calculations show a high blowing rate and a diverse representation of blowing species, as detailed in Ref. [53]. As mentioned earlier, LeMANS has previously been used to model Stardust and produces 
Table 3 Forward reaction rates for Olynick et al.'s [12] 18-species chemistry model

\begin{tabular}{|c|c|c|}
\hline No. & Reactions & References \\
\hline 1 & $\mathrm{CO}_{2}+\mathrm{M} \rightleftharpoons \mathrm{CO}+\mathrm{O}+\mathrm{M}$ & [39] \\
\hline 2 & $\mathrm{CO}+\mathrm{M} \rightleftharpoons \mathrm{C}+\mathrm{O}+\mathrm{M}$ & [39] \\
\hline 3 & $\mathrm{~N}_{2}+\mathrm{M} \rightleftharpoons 2 \mathrm{~N}+\mathrm{M}$ & [39] \\
\hline 4 & $\mathrm{O}_{2}+\mathrm{N}_{2} \rightleftharpoons \mathrm{NO}+\mathrm{NO}^{+}+\mathrm{e}^{-}$ & [39] \\
\hline 5 & $\mathrm{NO}+\mathrm{M} \rightleftharpoons \mathrm{N}+\mathrm{O}+\mathrm{M}$ & [39] \\
\hline 6 & $\mathrm{C}_{2}+\mathrm{M} \rightleftharpoons 2 \mathrm{C}+\mathrm{M}$ & [39] \\
\hline 7 & $\mathrm{C}_{3}+\mathrm{M} \rightleftharpoons \mathrm{C}+\mathrm{C}_{2}+\mathrm{M}$ & [50] \\
\hline 8 & $\mathrm{CN}+\mathrm{M} \rightleftharpoons \mathrm{C}+\mathrm{N}+\mathrm{M}$ & [39] \\
\hline 9 & $\mathrm{H}_{2}+\mathrm{M} \rightleftharpoons 2 \mathrm{H}+\mathrm{M}$ & ["51] \\
\hline 10 & $\mathrm{NO}+\mathrm{O} \rightleftharpoons \mathrm{O}_{2}+\mathrm{N}$ & [39] \\
\hline 11 & $\mathrm{~N}_{2}+\mathrm{O} \rightleftharpoons \mathrm{NO}+\mathrm{N}$ & [39] \\
\hline 12 & $\mathrm{CO}+\mathrm{O} \rightleftharpoons \mathrm{O}_{2}+\mathrm{C}$ & [39] \\
\hline 13 & $\mathrm{CO}_{2}+\mathrm{O} \rightleftharpoons \mathrm{CO}+\mathrm{O}_{2}$ & [39] \\
\hline 14 & $\mathrm{CO}+\mathrm{C} \rightleftharpoons \mathrm{C}_{2}+\mathrm{O}$ & [39] \\
\hline 15 & $\mathrm{CO}+\mathrm{N} \rightleftharpoons \mathrm{CN}+\mathrm{O}$ & [39] \\
\hline 16 & $\mathrm{~N}_{2}+\mathrm{C} \rightleftharpoons \mathrm{CN}+\mathrm{N}$ & [39] \\
\hline 17 & $\mathrm{CN}+\mathrm{O} \rightleftharpoons \mathrm{C}+\mathrm{NO}$ & [39] \\
\hline 18 & $\mathrm{CN}+\mathrm{C} \rightleftharpoons \mathrm{C}_{2}+\mathrm{N}$ & [39] \\
\hline 19 & $\mathrm{HCN}+\mathrm{H} \rightleftharpoons \mathrm{CN}+\mathrm{H}_{2}$ & 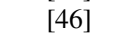 \\
\hline 20 & $\mathrm{C}+\mathrm{e}^{-} \rightleftharpoons \mathrm{C}^{+}+\mathrm{e}^{-}+\mathrm{e}^{-}$ & [49] \\
\hline 21 & $\mathrm{~N}+\mathrm{e}^{-} \rightleftharpoons \mathrm{N}^{+}+\mathrm{e}^{-}+\mathrm{e}^{-}$ & [49] \\
\hline 22 & $\mathrm{O}+\mathrm{e}^{-} \rightleftharpoons \mathrm{O}^{+}+\mathrm{e}^{-}+\mathrm{e}^{-}$ & [49] \\
\hline
\end{tabular}

Table 4 Free stream condition at $48 \mathrm{~s}$ during Stardust re-entry

\begin{tabular}{lc}
\hline \hline Parameter & Value \\
\hline$U_{\infty}, \mathrm{km} / \mathrm{s}$ & 11.414 \\
$T_{\infty}, \mathrm{K}$ & 230.8 \\
$\rho_{\infty}, \mathrm{kg} / \mathrm{m}^{3}$ & $1.4099 \times 10^{-4}$ \\
$Y_{\mathrm{N}_{2}}$ & 0.7635 \\
$Y_{\mathrm{O}_{2}}$ & 0.2365 \\
\hline \hline
\end{tabular}

Table 5 Predicted wall condition at stagnation point at $48 \mathrm{~s}$ during Stardust re-entry

\begin{tabular}{lc}
\hline \hline Parameter & Value \\
\hline$T_{w}, \mathrm{~K}$ & 3343.2 \\
$\dot{m}_{w}^{\prime \prime}, \mathrm{kg} /\left(\mathrm{m}^{2} \cdot \mathrm{s}\right)$ & 0.07277 \\
$Y_{\mathrm{N}_{2}}$ & 0.4670 \\
$X_{\mathrm{CO}}$ & 0.3200 \\
$Y_{\mathrm{C}_{2} \mathrm{H}}$ & 0.0752 \\
$Y_{\mathrm{C}_{3}}$ & 0.0489 \\
$Y_{\mathrm{CN}}$ & 0.0467 \\
$Y_{\mathrm{H}_{2}}$ & 0.0419 \\
\hline \hline
\end{tabular}

identical solutions [32] to the ones obtained using NASA Ames Research Center's DPLR [16].

The free stream flow and surface parameters are listed in Tables 4 and $\underline{5}$, and Fig. 1 presents the geometry and the corresponding mesh. The mesh contains $320 \times 486$ cells, and the first layer of cells near the surface of the vehicle has a thickness of approximately $2.5 \times 10^{-5} \mathrm{~m}$. To simplify the simulation, the flow is considered to be axisymmetric, and the wall temperature and blowing rates are applied uniformly on the surface. The Gibbs free energy of the reactive species is used to calculate the equilibrium constants needed for the backward reaction rates, and the transport properties are calculated from Lennard-Jones potentials, using CHEMKIN [54], to produce individual species temperature-dependant viscosity curve fits.

It is important to point out that the stagnation line results for each model (Figs. 2, 3, and 4) are extracted from the mesh using cellcentered information. Therefore, the values at the wall listed in Table $\mathbf{5}$ are not directly plotted.

\section{Park's 20-Species Model}

Figure 2a presents the stagnation line temperatures using the 20species model. As expected, the flow is in strong non-equilibrium, as can be seen in Fig. 2a. Figure 2 b shows the air species number density along the stagnation line as it goes through the shock. Figure $3 b$ shows that this particular test case has highly ionized flow, which suggests that $\mathrm{O}_{2}^{+}$should be present to better evaluate the shock. However, this species becomes insignificant post-shock. Figure 2c shows the non-air species along the stagnation line, and Fig. $2 \mathrm{~d}$ shows the same species in the region near the wall. Within $12 \mathrm{~mm}$ of the stagnation point, the number density of the species decreases sharply, indicating their rapid dissociation and atomization, once entering the post-shock region. The number density of $\mathrm{C}_{2}$ is much smaller than that of the other species in the model. This molecule is, however, quite important, as it provides the intermediate state to decompose $\mathrm{C}_{3}$ into $\mathrm{C}$ (through a combination of reactions 18, 19, and 20, and then reactions 2,17 , and 12) The observation that the number density of $\mathrm{C}_{2}$ is on the low-end while the number density of $\mathrm{C}_{3}$ is high-end is indicative of an incorrect set of dissociation reactions and rates for $\mathrm{C}_{3}$. The model only provides $\mathrm{C}_{3}$ dissociation by exchange reactions with atomic species that, due to the energetic barriers of initiation, are inefficient and incomplete under the simulated conditions. One interesting phenomenon to observe is the rapid ionization of $\mathrm{C}$ and $\mathrm{H}$, through reactions 8 and 9 . These two species are not generated at the surface, since the temperature is not high enough, and are therefore created by the dissociation of the larger molecules. As they are created, they immediately start to become ionized before being convected away.

\section{Suzuki's 26-Species Model}

The results for the 26-species [11] model are presented in Fig. 3. The boundary-layer composition predicted by this model, in comparison to Park et al.'s model [10], provides a more complete description of the undergoing chemistry. Large molecules composed of more than two atoms are quickly reduced; this behavior is a direct result of the additional reactions of Suzuki et al.'s model [11]. The rapid dissociation of both $\mathrm{C}_{3}$ and $\mathrm{C}_{2} \mathrm{H}$ species originating from the material is evident (Fig. 3c).

It is also interesting to note that $\mathrm{C}_{2} \mathrm{H}_{2}$ and $\mathrm{CO}_{2}$ are immediately created at the surface but rapidly disappear as they move away. Figure $3 \mathrm{f}$ also shows that, based on this single test case, excluding $\mathrm{CO}^{+}$might not be a bad assumption, as the number density never reaches a significant value even though $\mathrm{C}$ and $\mathrm{O}$ (the species needed to create $\mathrm{CO}^{+}$) are present in great quantity. The same conclusion cannot be drawn for $\mathrm{HCO}$, as this molecule could provide important reaction paths to other molecules: for instance, the reduction of $\mathrm{C}_{2} \mathrm{H}_{2}$ and $\mathrm{C}_{2}$ through reactions 45 and 46. As for $\mathrm{HCN}$, even if this particular test case does not include it as a blown species,
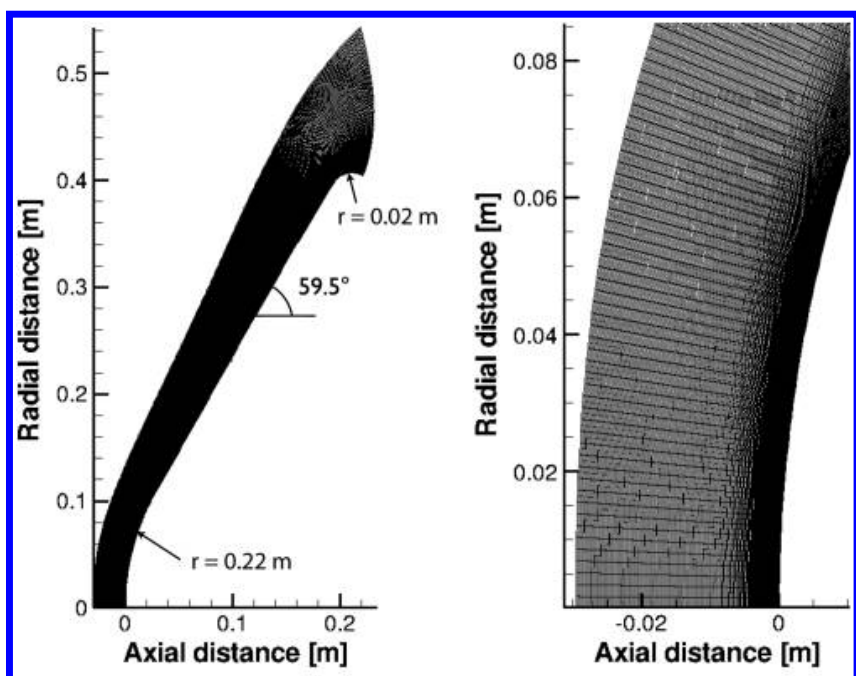

a) Geometry and overall mesh

b) Stagnation region mesh

Fig. 1 Geometry and mesh of the Stardust re-entry capsule used in the CFD calculations for the chemistry model comparison. 


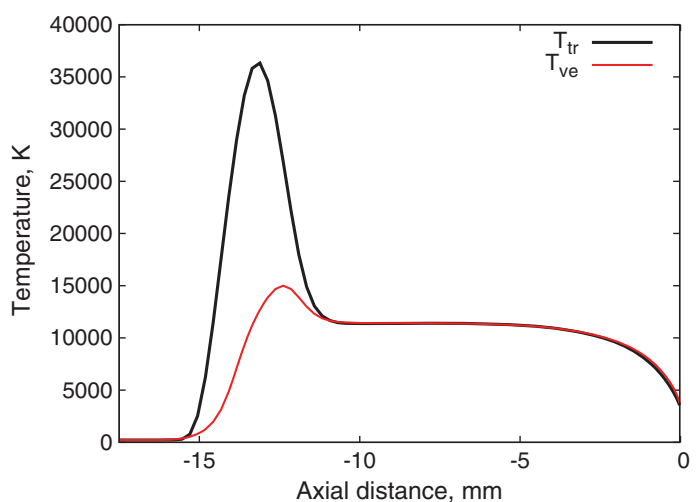

a) Translational-rotational temperature and vibrational-electron-electronic excitation temperature predictions

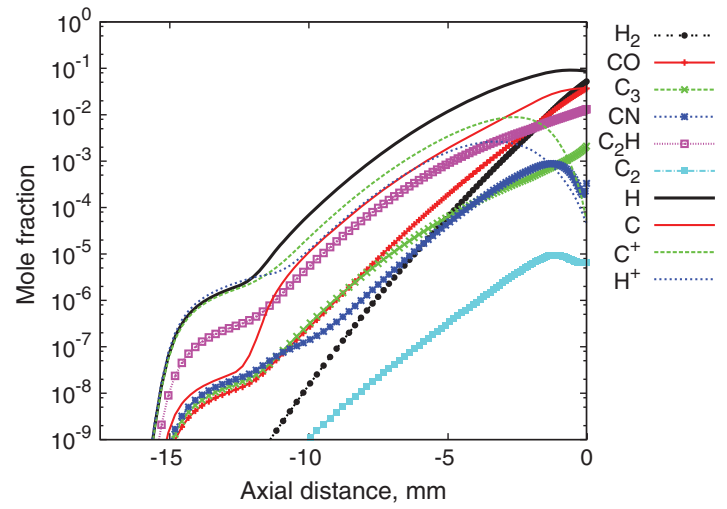

c) Predictions of the mole fractions for non-air species

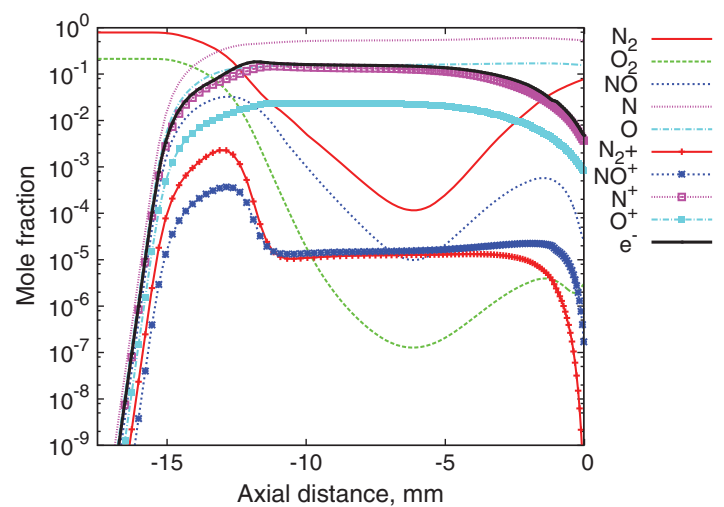

b) Predictions of the mole fractions for air species

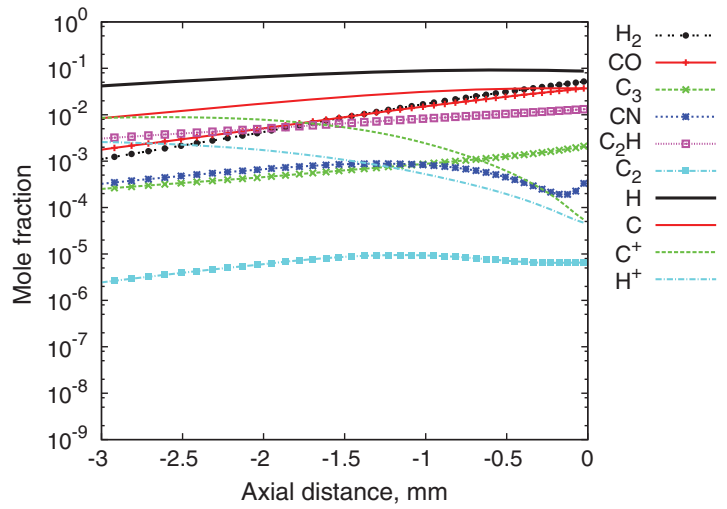

d) Predictions of the mole fractions for non-air species, near the wall

Fig. 2 Stagnation line CFD results using Park et al. [10], 48 s into Stardust's re-entry.

equilibrium composition studies show that it can be an important product of carbon-phenolic decomposition [53]. The same graph also shows that it is important to account for the $\mathrm{CH}$ molecule as it is rapidly created and becomes stable in the boundary layer. Since the $\mathrm{CH}$ dissociation reaction is not included in the model, the species does not decompose immediately.

\section{Olynick's 18-Species Model}

To be able to run this particular model in LeMANS, the electronimpact ionization rates are changed to the ones calculated and used by Park [22]; the rates provided in the original model were found to inadequate to be used efficiently in LeMANS, resulting in too stiff of a problem. The results along the stagnation streamline in the postshock region and the boundary layer are presented in Fig. 4. Even though dissociation reactions are present, the large molecules are not immediately reduced, similar to Park et al.'s model [22]. It is also interesting to see that $\mathrm{C}_{2}$ only appears in the shock region outside of the boundary layer, which is not the case with the two other models. This difference might be of importance, since $C_{2}$ is an important species due to its radiative properties.

As with the other models, the atomic species have the highest concentration near the wall. $\mathrm{HCN}$ is not present on the plot, as the only chemical reaction that involves it is more prone at reducing it than creating it at these conditions. For this model, the $\mathrm{C}_{2} \mathrm{H}$ molecule appears in unusually high quantities; the reason is that, even though this molecule exists in equilibrium at the wall, it has not been included in the chemistry model, and therefore is considered to be non-reacting in this simulation.

Finally, it is to be noted that both Olynick et al.'s [12] and Park et al.'s [10] models do not include the $\mathrm{CH}$ molecule and its associated reaction. As can be seen in the results obtained using Suzuki et al.'s model [11], $\mathrm{CH}$ might be an important species.

\section{Model Comparison: Heat Flux}

An important aspect of the analysis is the evaluation and comparison of the heat fluxes. The heat fluxes are obtained from the diffusive fluxes of the conservation energy equation, which is a quantity directly computed and used in finite volume methods [14]. The translation-rotation conduction heat flux, the vibrationalelectron-electronic excitation conduction heat flux, and the mass diffusion heat flux are, respectively, given by the quantities $\boldsymbol{q}_{\mathrm{tr}}, \boldsymbol{q}_{\mathrm{ve}}$, and $\boldsymbol{h}^{T} \boldsymbol{J}$ of Eq. (3). As was shown for the same geometry [12], using the Olynick et al. model [12], ablation significantly reduces the overall heat flux to the surface. The total convective heat flux, which includes conduction and mass diffusion, is presented in Fig. 5a. The discrepancy between models is quite significant, especially in the Suzuki et al. [11] model that is $24 \%$ smaller than the other two. Figures $5 \mathrm{~b}$ to $5 \mathrm{~d}$ show the individual components of the convective heat fluxes. It is not surprising to see that the 18- and 20-species models are nearly identical, as they share most of their sources for the kinetic rates. It can be noted that both models show very different boundary-layer compositions along the stagnation line. Although this difference in near-surface composition slightly impacts the mass diffusion heat flux, the most important difference is notable in the translation-rotation conductive heat flux because of the change in the thermal conductivity. To fully understand the specific difference between the two chemistry models and clearly identify the individual contributions to the change in thermal conductivity, it would be necessary to completely decouple the rotational and vibrational modes in the governing equation of the CFD code. 


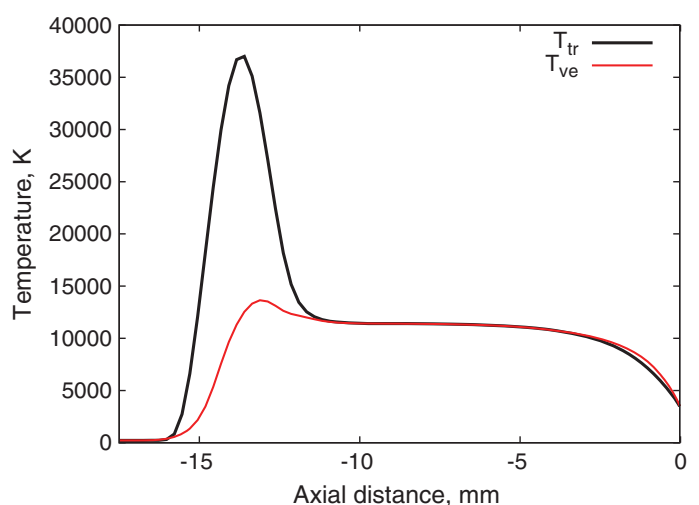

a) Translational-rotational temperature and vibrational-electron-electronic excitation temperatures predictions

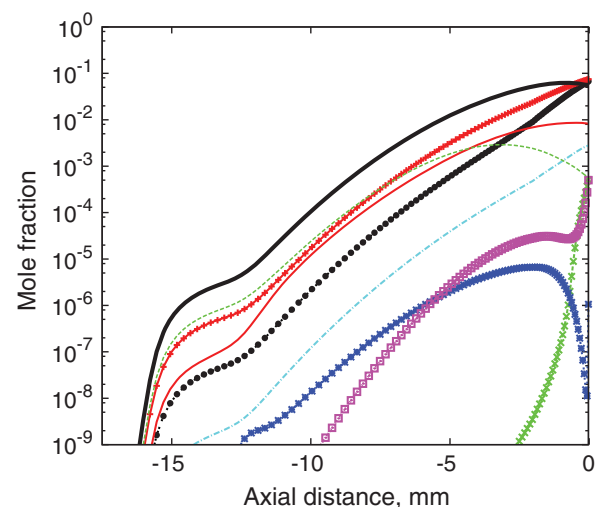

c) Predictions of the mole fractions for non-air species

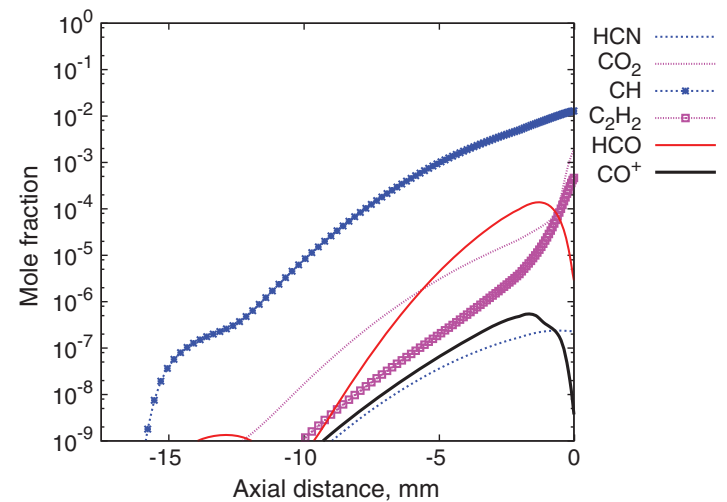

e) Predictions of the mole fractions for non-air species not in Park et al.'s [10] model

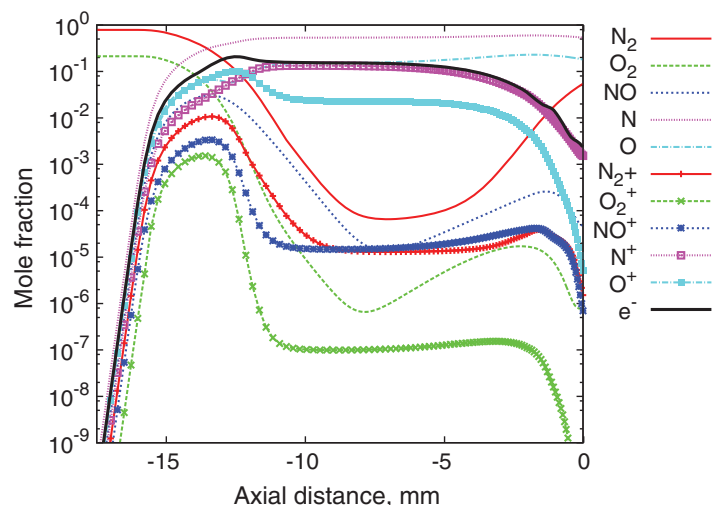

b) Predictions of the mole fractions for air species
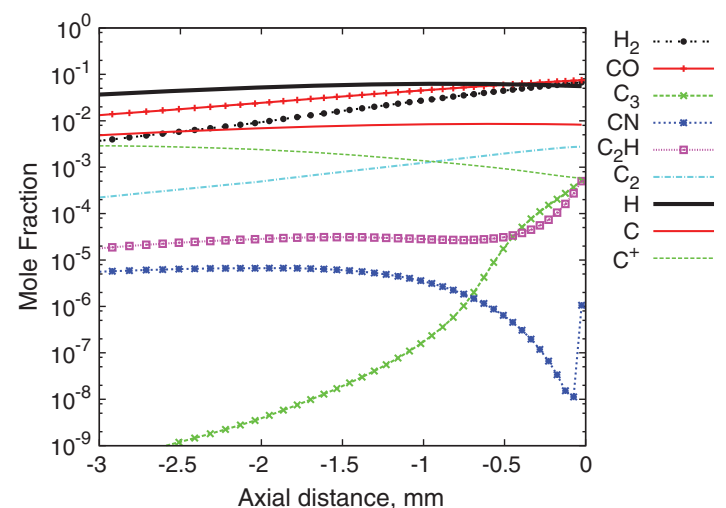

d) Predictions of the mole fractions for non-air species, near the wall

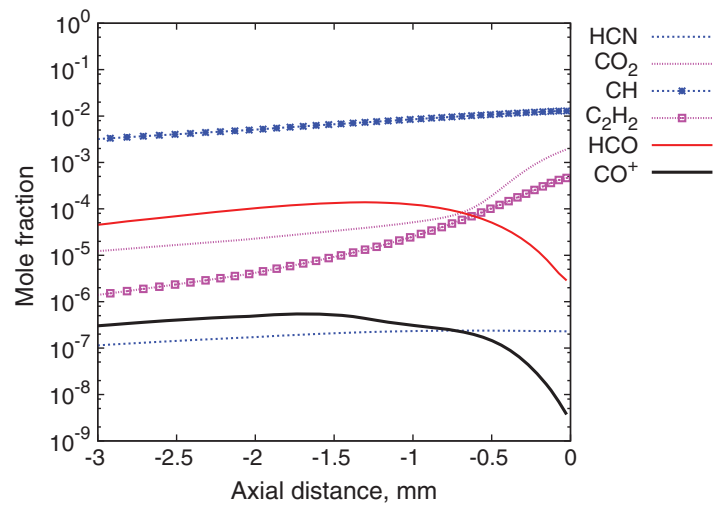

f) Predictions of the mole fractions for non-air species not in Park et al.'s [10] model, near the wall

Fig. 3 Stagnation line CFD results using Suzuki et al. [11], 48 s into Stardust's re-entry.

The radiative heat fluxes are also evaluated. Certain species, such as $\mathrm{CN}$ (see Figs. 2d, 3d, and 4d), present in the boundary layer are strong radiative emitters, and they are expected to significantly contribute to the overall radiative emission to the surface. The calculation is performed along the stagnation line of a converged flow field solution using the non-equilibrium radiation code NEQAIR2009 (version 7) [55]. Apart from the usual air species, the emission from the species listed in Table 6 is included. The heat flux is calculated by considering the emission at wavelengths between 200 and $1000 \mathrm{~nm}$ in order to avoid the uncertainties in the atomic vacuum ultraviolet spectral range.

The radiative calculation results are summarized in Table 7. First, it can be seen that the radiative flux contributes to a significant proportion of the total heat flux for all three models. Moreover, the differences in radiative heat flux between each model are quite pronounced, especially when comparing Suzuki et al.'s 26-species model [11] and the other two. This behavior is expected, as Olynick et al.'s [12] 18-species and Park et al.'s [10] 20-species models are very similar.

\section{Extensive Kinetic Model}

Following the results of the past section, it is clear that a new, more comprehensive model is needed. In the following section, such a model is built by first assembling an extensive baseline model that uses kinetic rates from the combustion literature. This extensive 


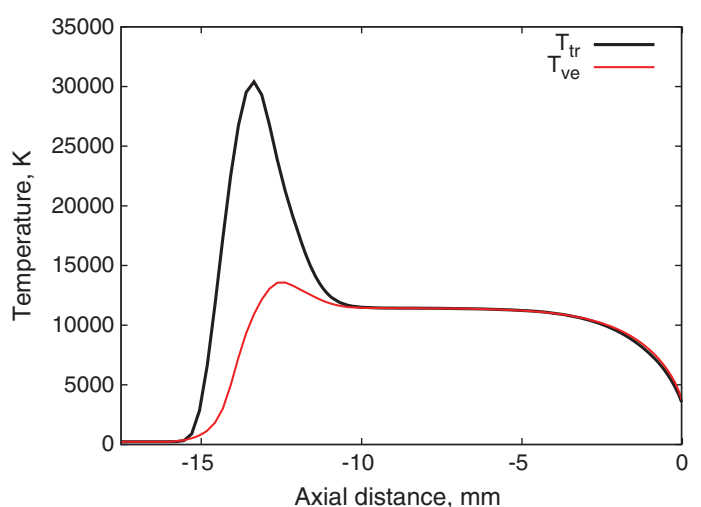

a) Translational-rotational temperature and vibrational-electron-electronic excitation temperatures predictions

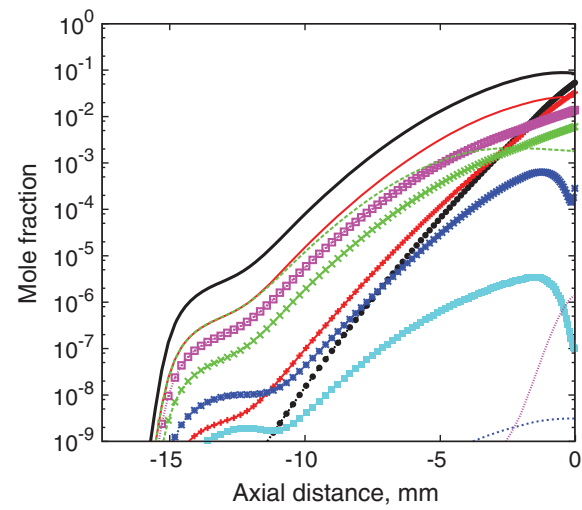

c) Predictions of the mole fractions for non-air species

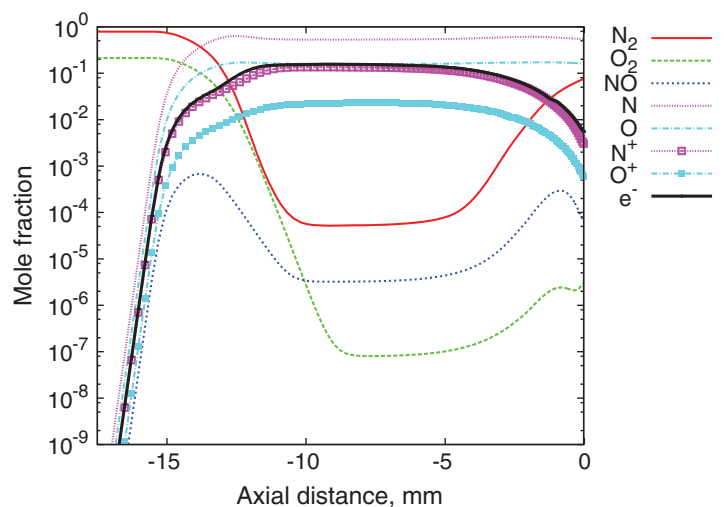

b) Predictions of the mole fractions for air species

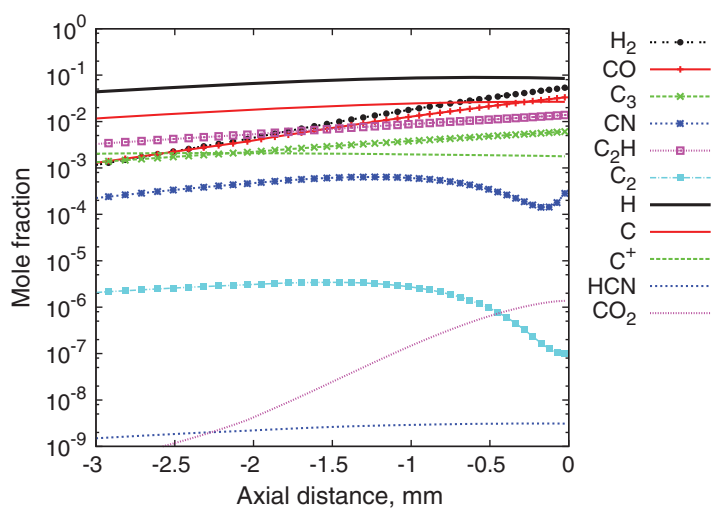

d) Predictions of the mole fractions for non-air species, near the wall

Fig. 4 Stagnation line CFD results using Olynick et al. [12], 48 s into Stardust's re-entry.

model is then reduced using sensitivity analysis to obtain a model that can be used in a computationally efficient manner in CFD codes. The new model is built using ionized air species and ablation species originating from a comprehensive analysis of Stardust and crew exploration vehicle $(\mathrm{CEV})$ trajectories.

\section{A. Species Selection}

1. Air Species

Because the model is intended to be used in Earth's atmosphere, it is therefore important to include all the molecules for ionizing air:

$$
\mathrm{N}_{2}, \mathrm{O}_{2}, \mathrm{NO}, \mathrm{N}, \mathrm{O}, \mathrm{N}_{2}^{+}, \mathrm{O}_{2}^{+}, \mathrm{NO}^{+}, \mathrm{N}^{+}, \mathrm{O}^{+}, \mathrm{e}^{-}
$$

\section{Ablation Species}

The surface ablation and pyrolysis of carbon-phenolic material is a complex chemistry problem. To evaluate the chemical composition at the surface, the re-entry trajectory of the Stardust vehicle and proposed trajectories of the CEV are used. One of the assumptions is that the gas is at thermochemical equilibrium at the surface. This assumption is necessary to perform the species selection analysis. It is, however, important to note that it might not be a perfect representation of the physical flow, since the chemical species coming from the atmospheric gas might be in non-equilibrium, yet the ones coming from the pyrolysis gas are probably in equilibrium.

The method of analysis for the thermal protection system begins with computing the flow field over a discrete set of points along the estimated flight trajectory to sufficiently capture the heat pulse. Highfidelity solutions are computed at several points in the trajectory with the CFD code DPLR [16]. For Stardust, these discrete solutions are interpolated in time (using engineering relationships) along the trajectory. The heat transfer coefficient, the surface pressure, and the free stream enthalpy are the environment inputs calculated for each surface point along the entire trajectory and used as input in the material response code FIAT [56]. For the CEV cases, the aerothermodynamic analysis tool CBAero [57] is used to provide the same input parameters.

For Stardust, only the conditions at the stagnation point are considered, whereas for the CEV, three surface locations are taken into account. In both cases, the contribution from the radiative heating $(\sim 10 \%)$ is neglected. The FIAT version 2.4 material response code [56] is used to model the PICA heat shield. The material properties (heat capacity, thermal conductivity, and emissivity) of the material in the TPS stack are read from the FIAT material database. The 3.3 version of the PICA [58] model is used in the present analysis; a representative composition, taken from Ref. [10], is shown in Table 8 . FIAT provides quantities such as surface temperature, density profiles, recession, ablation, and pyrolysis.

For selected time steps throughout the two analyzed trajectories, the pressure and the $B_{g}^{\prime}$ and $B_{c}^{\prime}$ values predicted by FIAT are then extracted and input to the multicomponent ablation thermochemistry (MAT) code [59]. Using this information, as well as the boundarylayer elemental composition of Table $\underline{8}$, MAT calculates from the $B^{\prime}$ tables the species mole fractions corresponding to the wall temperature predicted by FIAT, which are needed for input into LeMANS.

From these results, trajectories points are chosen so the widest possible combination of pressure and temperature is represented. Figure $\underline{6}$ shows the parameter space represented by those points. 


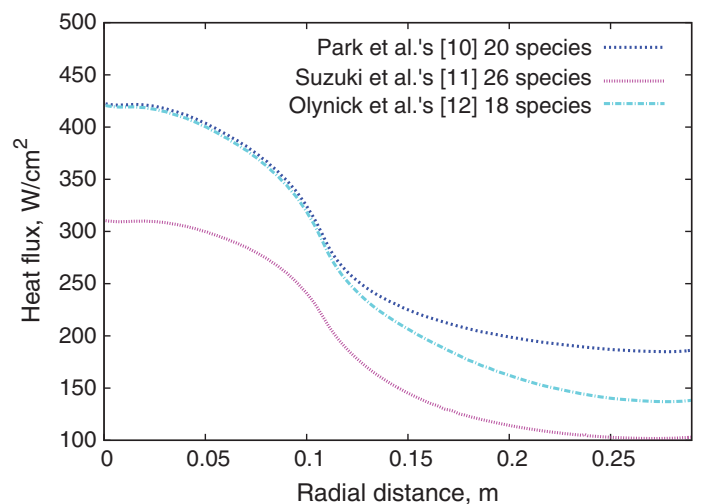

a) Comparison of the total heat flux for the three ablation models

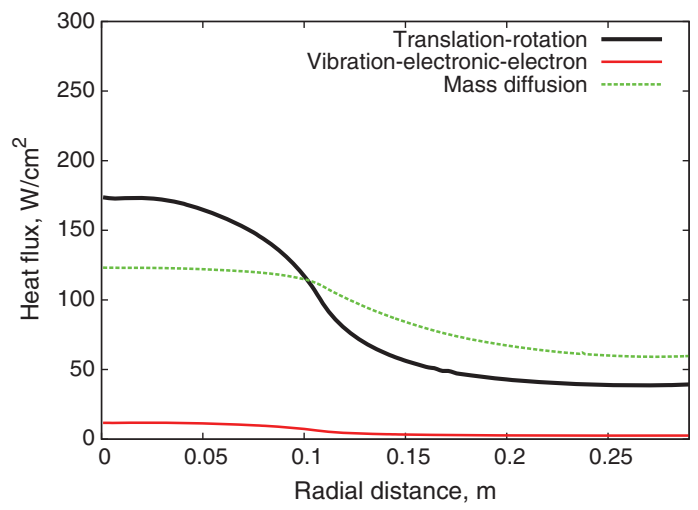

c) Separated components of the heat fluxes for Suzuki's model

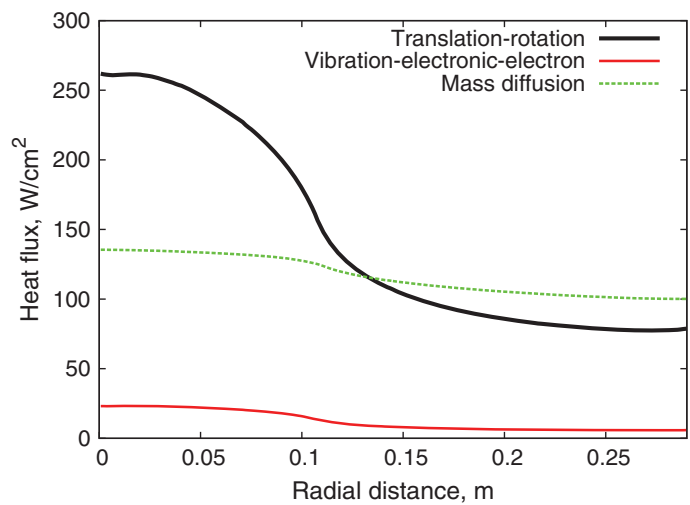

b) Separated components of the heat fluxes for Park's model

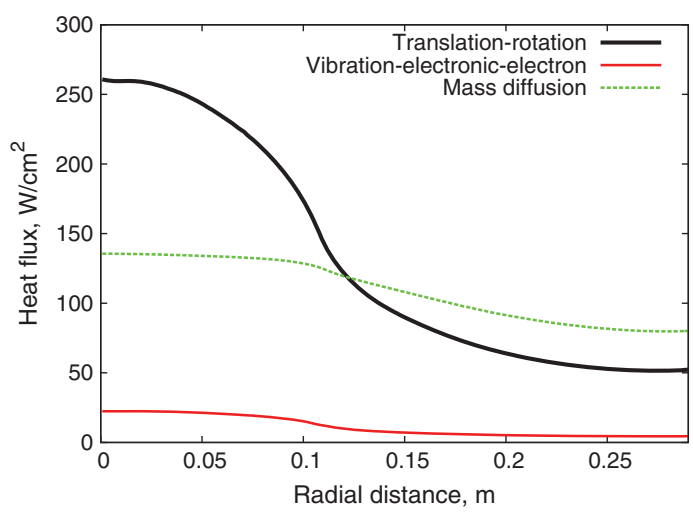

d) Separated components of the heat fluxes for Olynick's model

Fig. 5 CFD comparison of convective heat flux components for the three chemistry models, 48 s into Stardust's re-entry.

The MAT results are used to select which species are to be considered in the model; as listed in Table 9, only the species with the highest concentrations are kept. For each trajectory point, species mole fractions are added from the highest to the lowest value until the sum is greater than 0.999; all species not included in at least one trajectory point sum are eliminated. This ensures that the species chosen are representative of the actual computed values and that mass is conserved.

Table 6 Emission mechanisms considered for the radiative heat flux, excluding the air species

\begin{tabular}{lcc}
\hline \hline Species & Mechanism (electronic state transition) & Spectral range, $\mathrm{nm}$ \\
\hline $\mathrm{CN}$ & Violet $\left(B^{1} \Sigma-X^{1} \Sigma\right)$ & $230-462$ \\
$\mathrm{CO}$ & $4+\left(A^{1} \Pi-X^{1} \Sigma\right)$ & $110-385$ \\
$\mathrm{C}_{2}$ & Swan $\left(d^{3} \Pi-a^{4} \Pi\right)$ & $319-806$ \\
\hline \hline
\end{tabular}

Table 7 Comparison of radiative heat flux for the different chemistry model at wavelengths between 200 and $1000 \mathrm{~nm}$, at the condition corresponding to $48 \mathrm{~s}$ in the Stardust return capsule reentry trajectory

\begin{tabular}{lccc}
\hline \hline & $\begin{array}{c}\text { Radiative, } \\
\mathrm{W} / \mathrm{cm}^{2}\end{array}$ & $\begin{array}{c}\text { Convective, } \\
\mathrm{W} / \mathrm{cm}^{2}\end{array}$ & $\begin{array}{c}\text { Percent of } \\
\text { total flux, \% }\end{array}$ \\
\hline Park et al. [10] 20 species & 61.7 & 420 & 12.8 \\
Suzuki et al. [11] 26 species & 21.9 & 309 & 6.25 \\
Olynick et al. [12] 18 species & 52.6 & 420 & 11.1 \\
\hline \hline
\end{tabular}

Using this method, the following non-air species are selected:

$$
\mathrm{H}_{2}, \mathrm{CO}, \mathrm{CH}_{2}, \mathrm{H}_{2} \mathrm{O}, \mathrm{CO}_{2}, \mathrm{OH}, \mathrm{C}_{2} \mathrm{H}, \mathrm{C}_{2} \mathrm{H}_{2}, \mathrm{C}_{3}, \mathrm{CN}
$$

It should be noted that the error for trajectory point 17 is more than $0.1 \%$, at approximately $4 \%$. This is due to the fact that the JANNAF thermodynamic database, used in MAT, is outdated and gives inconsistent results for some situations. For instance, thermodynamic data used for the hydrocarbon molecules $\mathrm{C}_{3} \mathrm{H}$ and $\mathrm{C}_{4} \mathrm{H}$ date from early the 1960s [60] and have since been updated to very different values [61]. For instance, the $\mathrm{C}_{6} \mathrm{H}$ molecule was present, even though it should not appear from the equilibrium decomposition of phenol.

\section{Additional Boundary-Layer Species}

Ablation species are likely to be transformed as they travel through the boundary layer and into the post-shock layer. Therefore, it is important to include possible reaction paths leading to smaller molecules, as well as species from important reactions. The following

Table 8 Nominal elemental input conditions for the test case for ablating carbon phenolic [10] ${ }^{\mathrm{a}}$

\begin{tabular}{lcccc}
\hline \hline & Oxygen & Nitrogen & Hydrogen & Carbon \\
\hline Boundary-layer edge gas & 0.742 & 0.258 & 0.000 & 0.000 \\
Pyrolysis gas & 0.107 & 0.000 & 0.652 & 0.241 \\
Fully charred solid & 0.000 & 0.000 & 0.000 & 1.000 \\
\hline \hline
\end{tabular}

${ }^{\text {a }}$ The tabulated values are expressed in mole fractions. 


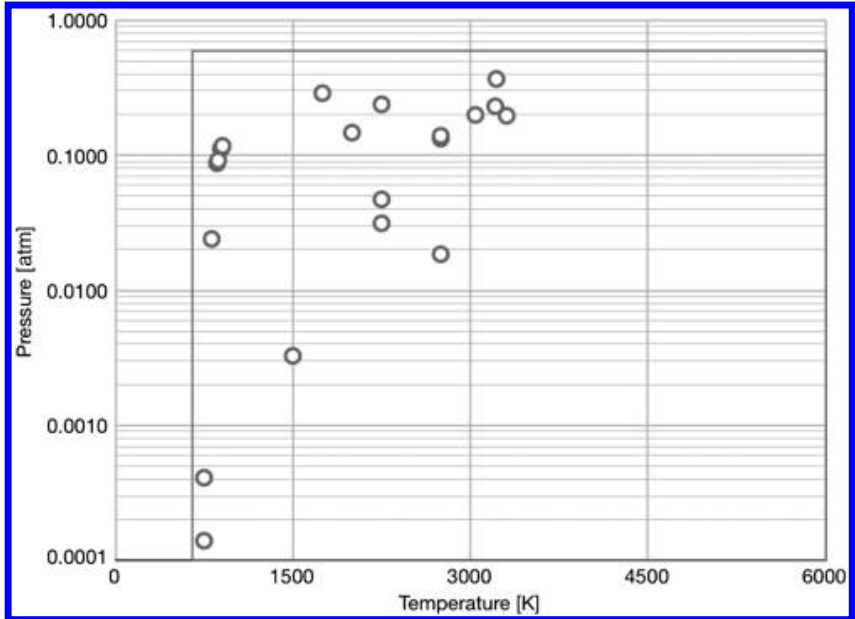

Fig. 6 Temperature vs pressure for various surface locations, trajectory points, and re-entry vehicles.

assumptions are made to include additional boundary-layer species of relevance.

1) A cross-check with the GRI-Mech database [62] identifies the following species as potentially reacting species under hypersonic conditions (high temperatures):

\section{$\mathrm{H}, \mathrm{NH}, \mathrm{HO}_{2}, \mathrm{H}_{2} \mathrm{O}_{2}, \mathrm{C}_{2} \mathrm{O}, \mathrm{HCN}, \mathrm{HCO}$}

as well as the hydrocarbon species:

$$
\text { C, } \mathrm{C}_{2}, \mathrm{CH}, \mathrm{CH}_{2}, \mathrm{CH}_{2}, \mathrm{C}_{2} \mathrm{H}_{2}, \mathrm{C}_{2} \mathrm{H}_{2}, \mathrm{C}_{2} \mathrm{H}_{2}, \mathrm{C}_{2} \mathrm{H}_{2}
$$

It is noteworthy to point out that the $\mathrm{HCN}$ molecule, identified earlier as a high-energy carrier $[\underline{11}, 22]$ present in very small mole fractions, is included.

2) For very high-speed reentries, such as Stardust, it is well known that ionized species are being formed and, as such, the chemistry model should account for them. Also, it is not uncommon for charged particles being generated in the shock layer to reach and be present in the boundary layer. Additionally, through associative ionization, electron-impact ionization, and charge exchange reactions, some of the carbon species from the pyrolysis gases could be ionized as well. The following species are thus selected for inclusion:

$$
\mathrm{CN}^{+}, \mathrm{CO}^{+}, \mathrm{C}^{+}, \mathrm{H}^{+}
$$

3) Because of the need to include the species listed under the earlier assumptions, the following molecules that are part of their decomposition/reaction mechanisms also need to be added:

$$
\mathrm{NNH}, \mathrm{HCCO}, \mathrm{NH}_{2}, \mathrm{NH}_{3}, \mathrm{NCO}, \mathrm{NO}_{2}, \mathrm{~N}_{2} \mathrm{O}, \mathrm{HNO}
$$

4) To ensure model compliance with ground tests, the following molecules are included in the data set (see Secs. IV.B and IV.C):

$$
\mathrm{Ar}, \mathrm{Ar}^{+}, C_{2} \mathrm{~N}_{2}, \mathrm{NCN}, \mathrm{C}_{2} \mathrm{~N}, \mathrm{C}_{3} \mathrm{O}_{2}
$$

Argon species are included because argon is the usual carrier gas for most experiments of this type; these are not expected to impact the reaction mechanism. The other species are the initial "cold" species used in the experiments; they are not expected to be created while reacting with other species in the temperature and pressure range of interest, and they usually dissociate instantaneously when passing through the shock.

Based on the aforementioned consideration, the constructed "extensive" baseline model includes 55 species.

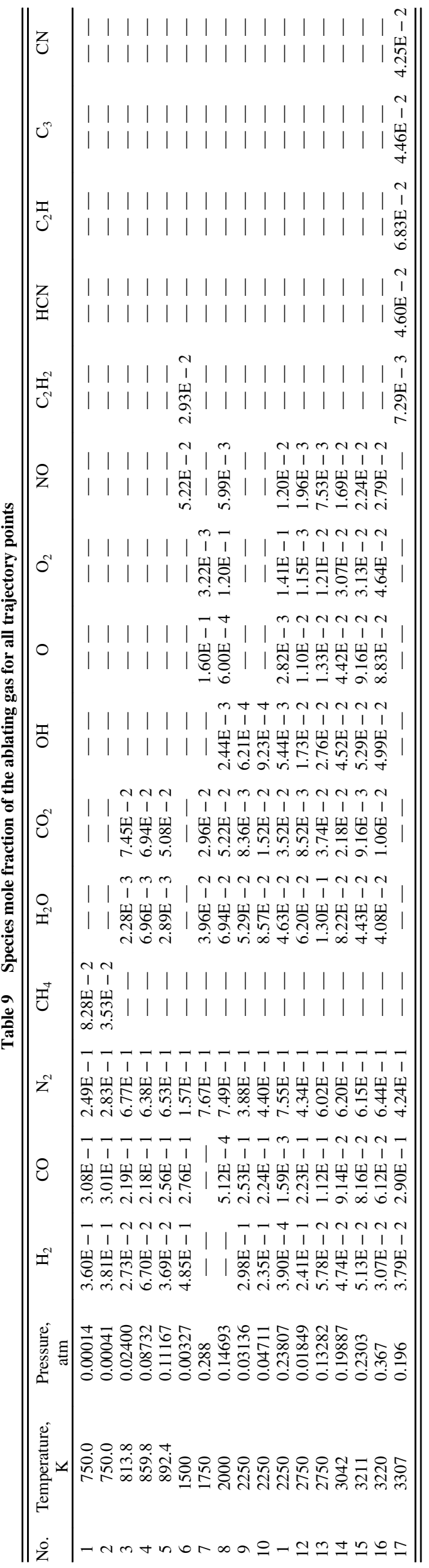


Table 10 Reactions and corresponding reaction parameters considered in the development of the extended chemistry model

\begin{tabular}{|c|c|c|c|c|}
\hline Reactions & $A, \mathrm{~mol} /(\mathrm{cm} \cdot \mathrm{s})$ & $n$ & $T_{a}, \mathrm{~K}$ & Reference \\
\hline $\mathrm{CN}+\mathrm{O} \rightleftharpoons \mathrm{CO}+\mathrm{N}$ & $2.04 \times 10^{13}$ & 0.0 & 210.0 & Louge and Hanson (1984) [63] \\
\hline $\mathrm{CN}+\mathrm{O} \rightleftharpoons \mathrm{CO}+\mathrm{N}$ & $3.00 \times 10^{13}$ & 0.0 & 0.0 & Mozzhukin et al. (1989) [6] \\
\hline $\mathrm{CN}+\mathrm{O} \rightleftharpoons \mathrm{CO}+\mathrm{N}$ & $6.20 \times 10^{12}$ & 0.0 & -1000.0 & Lindackers et al. (1990) $[\overline{65}]$ \\
\hline $\mathrm{CN}+\mathrm{O} \rightleftharpoons \mathrm{CO}+\mathrm{N}$ & $7.70 \times 10^{13}$ & 0.0 & 0.0 & 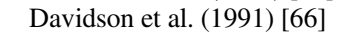 \\
\hline $\mathrm{CN}+\mathrm{O} \rightleftharpoons \mathrm{CO}+\mathrm{N}$ & $1.02 \times 10^{13}$ & 0.0 & 0.0 & Baulch et al. (1992) [67] \\
\hline $\mathrm{CO}+\mathrm{N} \rightleftharpoons \mathrm{CN}+\mathrm{O}$ & $1.00 \times 10^{14}$ & 0.0 & 38600.0 & Park et al. (2001) $[1 \overline{0]}$ \\
\hline $\mathrm{CO}+\mathrm{N} \rightleftharpoons \mathrm{CN}+\mathrm{O}$ & $2.41 \times 10^{14}$ & -0.18 & 0.0 & Andersson et al. (2003) [68] \\
\hline
\end{tabular}

\section{B. Reaction Selection}

\section{Primary Reaction Selection}

Reaction pathways of importance to thermal decomposition (pyrolysis) are synergistic with combustion. The reaction rates used to populate the extensive model employed to characterize the phenolic decomposition are thus taken from combustion databases. One of the most comprehensive and accurate such databases is GRIMech [62], developed by the University of California at Berkeley, Stanford University, and the University of Texas at Austin. The extensive model uses both kinetic rates for the chemical reactions as well as thermodynamic data to calculate backward rates.

The main drawback from these reaction rates is that they are only valid up to $5000 \mathrm{~K}$ : a temperature well below the temperature range of the gases outside the boundary layer. However, since the pyrolysis gases are not expected to enter regions of the flow where higher temperatures are reached (i.e., the shock layer), this assumption is reasonable for the current application. Moreover, all the reactions are carefully checked to make sure that, in case of extrapolation beyond their range of validity, the curve fit would produce physical results (i.e., the rate needs to increase with an increase in temperature). This is necessary, since the results from legacy models indicate that those species can diffuse into regions where the temperature is higher than $5000 \mathrm{~K}$; as shown, for instance, with the $\mathrm{C}_{2} \mathrm{H}$ and $\mathrm{CO}$ species in Figs. $2 \mathrm{~d}, 3 \mathrm{~d}$, and $4 \mathrm{~d}$. To account for the gases that are expected to be present in high-temperature regions, reaction rates relevant to those regions are replaced by those from Ref. [10] and Ref. [13], which were validated across a wide temperature range.

\section{Additional Reaction Selection}

A limited number of additional reaction rates relevant and validated for the regime of interest and not captured in the combustion database are added or updated in the model. One important aspect to note is that validated chemistry models are not a simple collection of chemical reactions: the reactions are calibrated as part of a more complex and intricately connected pathway. One should not attempt to change reactions and their corresponding parameters unless required by the specific applications. Such changes should be done by exerting extreme caution.

To have a closer look at some of those kinetic rates, results from a series of shock tube experiments are chosen with results from the numerical model. The experiments selected have test conditions that are relevant to an ablating boundary-layer environment and highlight kinetic rates and molecules that are important to the model. Most of these experiments were used to compute some of the chosen rates, but their ranges of validity might be limited. Therefore, the objective is to select rates that give satisfactory agreements with data from a wide range of experiments. To illustrate this effort, the reaction $\mathrm{CN}+\mathrm{O} \rightleftharpoons$ $\mathrm{CO}+\mathrm{N}$ is used. Since $\mathrm{CN}$ is a strong radiator, this reaction is one of the most important; therefore, many experiments were designed to try to determine its reaction rates. Each of the seven selected kinetic rates taken from Refs. $[10,63-68]$ and listed in Table 10 is used along with the extensive chemistry model described in the previous subsection to simulate two different experiments and to assess their accuracy. The listed kinetic rates $k$ are presented in a modified Arrhenius format using the following equation:

$$
k=A T^{n} e^{-T_{a} / T}
$$

As can be seen in Figs. $7 \mathrm{a}$ and $\underline{7 b}$, for experiments that are specifically designed to highlight the effects of kinetic rates, the changing of $\mathrm{CN} / \mathrm{CO}$ reaction rates leads to a wide variation of results when the two are compared. Although the variation in the $\mathrm{O}$ number density is reduced across models, the relative error for $\mathrm{CN}$ becomes almost one order of magnitude. In this particular case, it seems more appropriate to focus on the agreement for the $\mathrm{CN}$ species than to focus on $\mathrm{O}$, as $\mathrm{CN}$ tends to be more radiative. Consideration of relative errors also helps to select the best rate; for instance, since the $\mathrm{CN}$ mole fraction rapidly goes to zero, the relative error becomes very large, which is not the case in the other figure.

This analysis demonstrates that additional research on hightemperature chemistry is needed, whether it is experimental or theoretical. The reaction rates present in the literature do not cover the
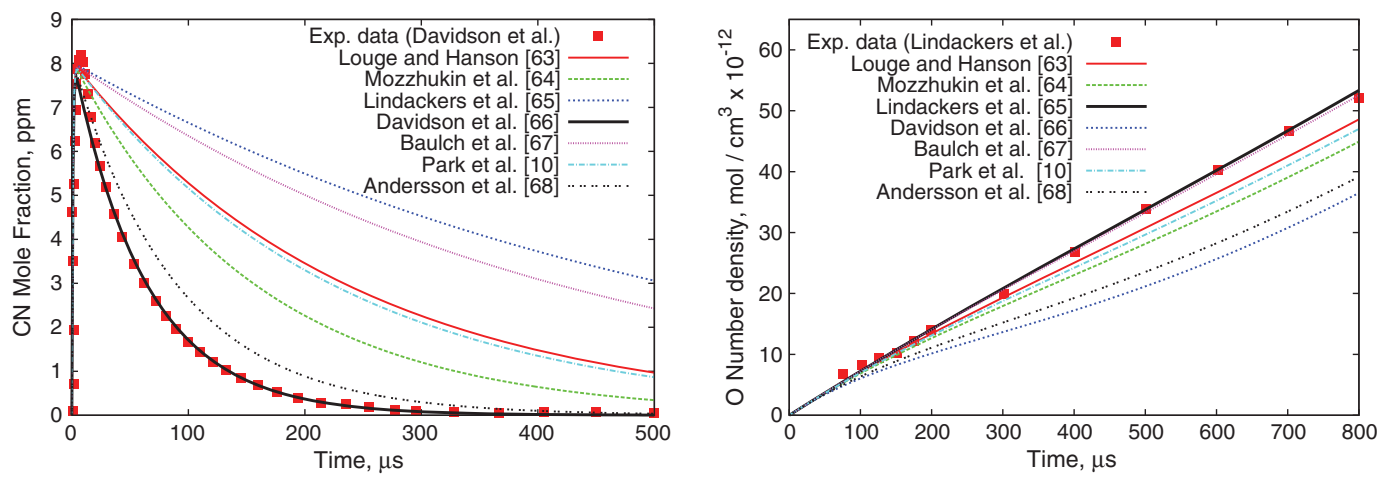

a) Comparison to the experiment of Ref. [66]: $T=4020 \mathrm{~K}$ $p=0.682 \mathrm{~atm}$, and $4 \mathrm{ppm}$ of $\mathrm{C}_{2} \mathrm{~N}_{2}$, and $100 \mathrm{ppm}$ of $\mathrm{N}_{2} \mathrm{O}$ in argon

b) Comparison to the experiment of Ref. [65]: $T=2966 \mathrm{~K}$, $p=1.579 \mathrm{~atm}$, and $5 \mathrm{ppm}$ of $\mathrm{C}_{2} \mathrm{~N}_{2}$, and $250 \mathrm{ppm}$ of $\mathrm{CO}_{2}$ in argon

Fig. 7 Comparison of the various kinetic reaction rates listed in Table 10 with experiments for the $\mathrm{CN}+\mathrm{O} \rightleftharpoons \mathrm{CO}+\mathrm{N}$ reaction. 
Table 11 Forward reaction rates for the reduced chemistry model for phenolic-based ablator decomposition in atmospheric air

\begin{tabular}{cccccc}
\hline \hline No. & Reaction & $A, \mathrm{~mol} /(\mathrm{cm} \cdot \mathrm{s})$ & $n$ & $T_{a}, \mathrm{~K}$ & References \\
\hline 1 & $2 \mathrm{HO}_{2} \rightleftharpoons \mathrm{O}_{2}+\mathrm{H}_{2} \mathrm{O}_{2}$ & $4.20 \times 10^{14}$ & 0.0 & $6,042.7$ & {$[\underline{62}]$} \\
2 & $2 \mathrm{OH}+\mathrm{M} \rightleftharpoons \mathrm{H}_{2} \mathrm{O}_{2}+\mathrm{M}$ & $2.30 \times 10^{18}$ & -0.9 & $-1,700.0$ & {$[\underline{62}]$}
\end{tabular}

$\mathrm{H}_{2}$ enhanced by 2.00

$\mathrm{H}_{2} \mathrm{O}$ enhanced by 6.00

$\mathrm{CH}_{4}$ enhanced by 2.00

$\mathrm{CO}, \mathrm{CO}^{+}$enhanced by 1.50

$\mathrm{CO}_{2}$ enhanced by 2.00

Ar enhanced by 0.38

$2 \mathrm{OH} \rightleftharpoons \mathrm{O}+\mathrm{H}_{2} \mathrm{O}$

$\mathrm{C}+e \rightleftharpoons \mathrm{C}^{+}+e+e$

$\mathrm{C}+\mathrm{H}_{2} \rightleftharpoons \mathrm{CH}+\mathrm{H}$

$\mathrm{C}+\mathrm{N}_{2} \rightleftharpoons \mathrm{CN}+\mathrm{N}$

$\mathrm{C}+\mathrm{NO} \rightleftharpoons \mathrm{CN}+\mathrm{O}$

$\mathrm{C}+\mathrm{NO} \rightleftharpoons \mathrm{CO}+\mathrm{N}$

$\mathrm{C}+\mathrm{O} \rightleftharpoons \mathrm{CO}^{+}+\mathrm{e}$

$\mathrm{C}+\mathrm{O}_{2} \rightleftharpoons \mathrm{O}+\mathrm{CO}$

$\mathrm{C}_{2}+\mathrm{C}_{2} \rightleftharpoons \mathrm{C}_{3}+\mathrm{C}$

$\mathrm{C}_{2}+\mathrm{H}_{2} \rightleftharpoons \mathrm{C}_{2} \mathrm{H}+\mathrm{H}$

$\mathrm{C}_{2}+\mathrm{N}_{2} \rightleftharpoons \mathrm{CN}+\mathrm{CN}$

$\mathrm{C}_{2} \mathrm{H}+\mathrm{M} \rightleftharpoons \mathrm{C}_{2}+\mathrm{H}+\mathrm{M}$

$\mathrm{C}_{2} \mathrm{H}+\mathrm{C} \rightleftharpoons \mathrm{C}_{3}+\mathrm{H}$

$\mathrm{C}_{2} \mathrm{H}_{2}+\mathrm{M} \rightleftharpoons \mathrm{C}_{2} \mathrm{H}+\mathrm{H}+\mathrm{M}$

$\mathrm{C}_{2}+\mathrm{M} \rightleftharpoons 2 \mathrm{C}+\mathrm{M}$

$\mathrm{CH}+\mathrm{C} \rightleftharpoons \mathrm{C}_{2}+\mathrm{H}$

$\mathrm{CH}+\mathrm{CH} \rightleftharpoons \mathrm{C}_{2} \mathrm{H}+\mathrm{H}$

$\mathrm{CH}+\mathrm{CO}_{2} \rightleftharpoons \mathrm{HCO}+\mathrm{CO}$

$\mathrm{CH}+\mathrm{M} \rightleftharpoons \mathrm{C}+\mathrm{H}+\mathrm{M}$

$\mathrm{CH}+\mathrm{N}_{2} \rightleftharpoons \mathrm{HCN}+\mathrm{N}$

$\mathrm{CH}+\mathrm{O}_{2} \rightleftharpoons \mathrm{O}+\mathrm{HCO}$

$\mathrm{CH}_{2}+\mathrm{C} \rightleftharpoons \mathrm{C}_{2} \mathrm{H}+\mathrm{H}$

$\mathrm{CH}_{2}+\mathrm{CH} \rightleftharpoons \mathrm{C}_{2} \mathrm{H}_{2}+\mathrm{H}$

$\mathrm{CH}_{2}+\mathrm{CH}_{2} \rightleftharpoons \mathrm{C}_{2} \mathrm{H}_{2}+\mathrm{H}+\mathrm{H}$

$\mathrm{CH}_{2}+\mathrm{CH}_{2} \rightleftharpoons \mathrm{C}_{2} \mathrm{H}_{2}+\mathrm{H}_{2}$

$\mathrm{CH}_{2}+\mathrm{CH}_{4} \rightleftharpoons \mathrm{CH}_{3}+\mathrm{CH}_{3}$

$\mathrm{CH}_{2}+\mathrm{H} \rightleftharpoons \mathrm{CH}+\mathrm{H}_{2}$

$\mathrm{CH}_{2}+\mathrm{M} \rightleftharpoons \mathrm{C}+\mathrm{H}_{2}+\mathrm{M}$

$\mathrm{CH}_{2}+\mathrm{M} \rightleftharpoons \mathrm{CH}+\mathrm{H}+\mathrm{M}$

$\mathrm{CH}_{2}+\mathrm{N} \rightleftharpoons \mathrm{HCN}+\mathrm{H}$

$\mathrm{CH}_{2}+\mathrm{N}_{2} \rightleftharpoons \mathrm{HCN}+\mathrm{NH}$

$\mathrm{CH}_{2}+\mathrm{NO} \rightleftharpoons \mathrm{OH}+\mathrm{HCN}$

$\mathrm{CH}_{3}+\mathrm{C} \rightleftharpoons \mathrm{C}_{2} \mathrm{H}_{2}+\mathrm{H}$

$\mathrm{CH}_{3}+\mathrm{H} \rightleftharpoons \mathrm{CH}_{2}+\mathrm{H}_{2}$

$\mathrm{CH}_{3}+\mathrm{HCO} \rightleftharpoons \mathrm{CH}_{4}+\mathrm{CO}$

$\mathrm{CH}_{3}+\mathrm{M} \rightleftharpoons \mathrm{CH}+\mathrm{H}_{2}+\mathrm{M}$

$\mathrm{CH}_{3}+\mathrm{M} \rightleftharpoons \mathrm{CH}_{2}+\mathrm{H}+\mathrm{M}$

$\mathrm{CH}_{3}+\mathrm{N} \rightleftharpoons \mathrm{HCN}+\mathrm{H}+\mathrm{H}$

$\mathrm{CH}_{3}+\mathrm{N} \rightleftharpoons \mathrm{HCN}+\mathrm{H}_{2}$

$\mathrm{CH}_{3}+\mathrm{NO} \rightleftharpoons \mathrm{HCN}+\mathrm{H}_{2} \mathrm{O}$

$\mathrm{CH}_{4}+\mathrm{M} \rightleftharpoons \mathrm{CH}_{3}+\mathrm{H}+\mathrm{M}$ $\mathrm{CN}+\mathrm{C} \rightleftharpoons \mathrm{C}_{2}+\mathrm{N}$

$\mathrm{CN}+\mathrm{CO} \rightleftharpoons \mathrm{C}+\mathrm{NCO}$

$\mathrm{CN}+\mathrm{CO}_{2} \rightleftharpoons \mathrm{CO}+\mathrm{NCO}$

$\mathrm{CN}+\mathrm{H}_{2} \rightleftharpoons \mathrm{HCN}+\mathrm{H}$

$\mathrm{CN}+\mathrm{H}_{2} \mathrm{O} \rightleftharpoons \mathrm{HCN}+\mathrm{OH}$

$\mathrm{CN}+\mathrm{M} \rightleftharpoons \mathrm{C}+\mathrm{N}+\mathrm{M}$

$\mathrm{CN}+\mathrm{NO} \rightleftharpoons \mathrm{N}+\mathrm{NCO}$

$\mathrm{CN}+\mathrm{O} \rightleftharpoons \mathrm{CO}+\mathrm{N}$

$\mathrm{CN}+\mathrm{O}_{2} \rightleftharpoons \mathrm{O}+\mathrm{NCO}$

$\mathrm{CN}+\mathrm{OH} \rightleftharpoons \mathrm{NCO}+\mathrm{H}$

$\mathrm{CN}^{+}+\mathrm{N} \rightleftharpoons \mathrm{CN}+\mathrm{N}^{+}$

$\mathrm{C}+\mathrm{N} \rightleftharpoons \mathrm{CN}^{+}+e$

$\mathrm{CO}+\mathrm{C}^{+} \rightleftharpoons \mathrm{CO}^{+}+\mathrm{C}$

$\mathrm{CO}+\mathrm{M} \rightleftharpoons \mathrm{O}+\mathrm{C}+\mathrm{M}$

$\mathrm{CO}_{2}+\mathrm{M} \rightleftharpoons \mathrm{O}+\mathrm{CO}+\mathrm{M}$

$\mathrm{CO}_{2}+\mathrm{O} \rightleftharpoons \mathrm{CO}+\mathrm{O}_{2}$

$\mathrm{H}+\mathrm{C}_{2} \mathrm{H}_{2} \rightleftharpoons \mathrm{C}_{2} \mathrm{H}+\mathrm{H}_{2}$

$\mathrm{H}+e \rightleftharpoons \mathrm{H}^{+}+e+e$

$\mathrm{H}+\mathrm{CH}_{4} \rightleftharpoons \mathrm{CH}_{3}+\mathrm{H}_{2}$

$\mathrm{H}+\mathrm{H}_{2} \mathrm{O}_{2} \rightleftharpoons \mathrm{HO}_{2}+\mathrm{H}_{2}$

$\mathrm{H}+\mathrm{H}_{2} \mathrm{O}_{2} \rightleftharpoons \mathrm{OH}+\mathrm{H}_{2} \mathrm{O}$
$3.57 \times 10^{4}$

$3.7 \times 10^{31}$

$4.00 \times 10^{14}$

$5.24 \times 10^{13}$

$2.02 \times 10^{14}$

$2.29 \times 10^{13}$

$8.80 \times 10^{8}$

$5.80 \times 10^{13}$

$3.20 \times 10^{14}$

$6.60 \times 10^{13}$

$1.50 \times 10^{13}$

$1.74 \times 10^{35}$

$1.00 \times 10^{14}$

$6.96 \times 10^{39}$

$1.50 \times 10^{16}$

$2.00 \times 10^{14}$

$1.50 \times 10^{14}$

$1.90 \times 10^{14}$

$1.90 \times 10^{14}$

$4.40 \times 10^{12}$

$6.71 \times 10^{13}$

$5.00 \times 10^{13}$

$4.00 \times 10^{13}$

$2.00 \times 10^{14}$

$1.58 \times 10^{15}$

$4.30 \times 10^{12}$

$6.03 \times 10^{12}$

$1.30 \times 10^{14}$

$4.00 \times 10^{15}$

$5.00 \times 10^{13}$

$4.82 \times 10^{12}$

$2.90 \times 10^{14}$

$5.00 \times 10^{13}$

$6.03 \times 10^{13}$

$1.21 \times 10^{14}$

$5.00 \times 10^{15}$

$1.02 \times 10^{16}$

$7.00 \times 10^{13}$

$3.70 \times 10^{12}$

$9.60 \times 10^{13}$

$4.70 \times 10^{47}$

$5.00 \times 10^{13}$

$1.50 \times 10^{16}$

$4.00 \times 10^{14}$

$2.95 \times 10^{5}$

$8.00 \times 10^{12}$

$2.53 \times 10^{14}$

$2.00 \times 10^{13}$

$2.41 \times 10^{14}$

$1.05 \times 10^{13}$

$4.00 \times 10^{13}$

$9.80 \times 10^{12}$

$1.00 \times 10^{15}$

$1.0 \times 10^{13}$

$2.30 \times 10^{19}$

$\mathrm{C}, \mathrm{C}^{+}$enhanced by 1.50

$\mathrm{N}, \mathrm{N}^{+}$enhanced by 1.50

$\mathrm{O}, \mathrm{O}^{+}$enhanced by 1.50

$\mathrm{H}, \mathrm{H}^{+}$enhanced by 1.50

$3.50 \times 10^{14}$

$2.10 \times 10^{13}$

$6.62 \times 10^{13}$

$2.2 \times 10^{22}$

$1.32 \times 10^{4}$

$1.21 \times 10^{7}$

$1.00 \times 10^{13}$

\begin{tabular}{|c|c|c|}
\hline 2.4 & $-1,062.5$ & [62] \\
\hline-3.0 & 130,720 & {$[\overline{13}]$} \\
\hline 0.0 & $11,700.0$ & {$[\overline{73}]$} \\
\hline 0.0 & $22,600.0$ & {$[\overline{74}]$} \\
\hline-0.3 & 0.0 & {$[\overline{68}]$} \\
\hline 0.0 & 0.0 & {$[\overline{68}]$} \\
\hline 1.0 & $33,100.0$ & {$[\overline{10}]$} \\
\hline 0.0 & 576.0 & {$[\overline{62}]$} \\
\hline 0.0 & 0.0 & {$[\overline{75}]$} \\
\hline 0.0 & $4,030.0$ & {$[\overline{75}]$} \\
\hline 0.0 & $21,000.0$ & {$[\overline{76}]$} \\
\hline-5.2 & $57,400.0$ & {$[\overline{75}]$} \\
\hline 0.0 & 0.0 & [72] \\
\hline-6.1 & $57,370.2$ & [75] \\
\hline 0.0 & 71,662 & {$[\overline{75}]$} \\
\hline 0.0 & 0.0 & {$[\overline{72}]$} \\
\hline 0.0 & 0.0 & {$[\overline{72}]$} \\
\hline 0.0 & $7,952.1$ & {$[\overline{62}]$} \\
\hline 0.0 & $33,700.0$ & {$[\overline{72}]$} \\
\hline 0.0 & $11,060.0$ & {$[\overline{77}]$} \\
\hline 0.0 & 0.0 & [62] \\
\hline 0.0 & 0.0 & {$[\overline{72}]$} \\
\hline 0.0 & 0.0 & [7]2] \\
\hline 0.0 & $5,530.0$ & [78] \\
\hline 0.0 & $6,010.0$ & [78] \\
\hline 0.00 & $5,050.0$ & {$[\overline{79}]$} \\
\hline 0.0 & -900.0 & [67] \\
\hline 0.0 & $29,700.0$ & {$[\overline{72}]$} \\
\hline 0.0 & $41,800.0$ & [72] \\
\hline 0.0 & 0.0 & [7]7] \\
\hline 0.0 & $18,000.0$ & {$[\overline{80}]$} \\
\hline-0.69 & 382.70 & {$[\overline{62}]$} \\
\hline 0.0 & 0.0 & [72] \\
\hline 0.0 & $7,600.0$ & [67] \\
\hline 0.0 & 0.0 & [81] \\
\hline 0.0 & $42,800.0$ & [72] \\
\hline 0.0 & $45,600.0$ & [67] \\
\hline 0.0 & 0.0 & {$[\overline{77}]$} \\
\hline 0.1 & -45.3 & {$[\overline{62}]$} \\
\hline 0.00 & $14,502.41$ & [62] \\
\hline-8.2 & $59,200.0$ & {$[\overline{74}]$} \\
\hline 0.0 & $13,000.0$ & [39] \\
\hline-0.5 & $65,800.0$ & [10] \\
\hline 0.0 & $19,200.0$ & [10] \\
\hline 2.5 & $1,130.0$ & {$[\overline{62}]$} \\
\hline 0.0 & $3,756.5$ & {$[\overline{62}]$} \\
\hline 0.0 & $71,000.0$ & {$[\overline{39}]$} \\
\hline 0.0 & $21,000.0$ & {$[\overline{73}]$} \\
\hline-0.2 & 0.0 & {$[\overline{68}]$} \\
\hline 0.0 & 0.0 & [66] \\
\hline 0.0 & 0.0 & [62] \\
\hline 0.0 & 40,700 & [13] \\
\hline 1.50 & 164,000 & {$[\overline{13}]$} \\
\hline 0.00 & $31,400.0$ & [39] \\
\hline-1.0 & $129,000.0$ & [39] \\
\hline
\end{tabular}

$0.0 \quad 52,525.0$

$0.0 \quad 27,800.0$

$0.0 \quad 14,000.0$

$-2.8 \quad 157,800$

$3.0 \quad 4,045.0$

$2.0 \quad 2,618.5$

$0.0 \quad 1,812.8$ 
Table 11 (Continued.)

\begin{tabular}{cc}
\hline \hline No. & Reaction \\
\hline 65 & $\mathrm{H}+\mathrm{HCO} \rightleftharpoons \mathrm{H}_{2}+\mathrm{CO}$ \\
66 & $\mathrm{H}+\mathrm{HO}_{2} \rightleftharpoons 2 \mathrm{OH}$ \\
67 & $\mathrm{H}+\mathrm{HO}_{2} \rightleftharpoons \mathrm{O}+\mathrm{H}_{2} \mathrm{O}$ \\
68 & $\mathrm{H}+\mathrm{HO}_{2} \rightleftharpoons \mathrm{O}_{2}+\mathrm{H}_{2}$ \\
69 & $\mathrm{H}+\mathrm{N}_{2} \rightleftharpoons \mathrm{NH}+\mathrm{N}$ \\
70 & $\mathrm{H}+\mathrm{NO}+\mathrm{M} \rightleftharpoons \mathrm{HNO}+\mathrm{M}$ \\
& \\
& \\
& \\
& \\
& \\
71 & $\mathrm{H}+\mathrm{O}_{2}+\mathrm{M} \rightleftharpoons \mathrm{HO}_{2}+\mathrm{M}$ \\
& \\
& \\
& \\
& \\
& \\
72 & $\mathrm{H}+\mathrm{O}_{2}+\mathrm{N}_{2} \rightleftharpoons \mathrm{HO}_{2}+\mathrm{N}_{2}$ \\
73 & $\mathrm{H}+\mathrm{O}_{2}+\mathrm{N}_{2}^{+} \rightleftharpoons \mathrm{HO}_{2}+\mathrm{N}_{2}^{+}$ \\
74 & $\mathrm{H}+2 \mathrm{O}_{2} \rightleftharpoons \mathrm{HO}_{2}+\mathrm{O}_{2}$ \\
75 & $\mathrm{H}+2 \mathrm{O}_{2}^{+} \rightleftharpoons \mathrm{HO}_{2}+\mathrm{O}_{2}^{+}$ \\
76 & $\mathrm{H}+\mathrm{O}_{2}+\mathrm{H}_{2} \mathrm{O} \rightleftharpoons \mathrm{HO}_{2}+\mathrm{H}_{2} \mathrm{O}$ \\
77 & $\mathrm{H}+\mathrm{O}_{2} \rightleftharpoons \mathrm{O}^{2}+\mathrm{OH}$ \\
78 & $\mathrm{H}+\mathrm{OH}^{2}+\mathrm{M}_{2} \rightleftharpoons \mathrm{H}_{2} \mathrm{O}+\mathrm{M}$
\end{tabular}
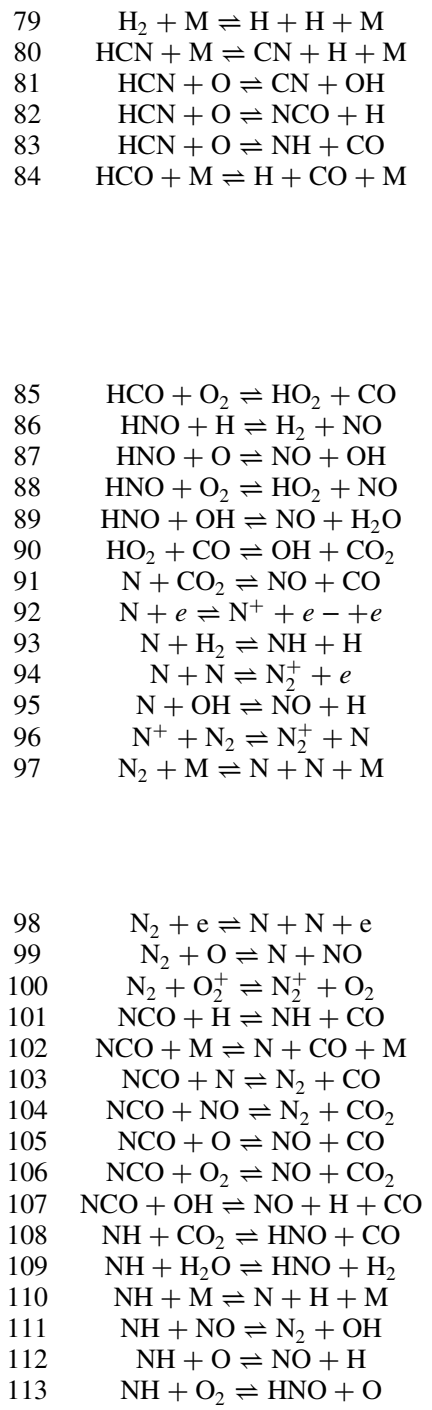

$\mathrm{H}_{2}$ enhanced by 2.00

$\mathrm{H}_{2} \mathrm{O}$ enhanced by 6.00

$\mathrm{CH}_{4}$ enhanced by 2.00

$\mathrm{CO}, \mathrm{CO}^{+}$enhanced by 1.50

$\mathrm{CO}_{2}$ enhanced by 2.00

Ar enhanced by 0.7 $2.80 \times 10^{18}$

$\mathrm{O}_{2}, \mathrm{O}_{2}^{+}$enhanced by 0.00

$\mathrm{H}_{2} \mathrm{O}$ enhanced by 0.00

$\mathrm{CO}, \mathrm{CO}^{+}$enhanced by 0.75

$\mathrm{CO}_{2}$ enhanced by 1.50

$\mathrm{N}_{2}, \mathrm{~N}_{2}^{+}$enhanced by 0.00

Ar enhanced by 0.0

$2.60 \times 10^{19}$
$2.60 \times 10^{19}$
$2.08 \times 10^{19}$
$2.08 \times 10^{19}$
$1.13 \times 10^{19}$
$2.65 \times 10^{16}$
$2.20 \times 10^{22}$

$\mathrm{H}_{2}$ enhanced by 0.73

$\mathrm{H}_{2} \mathrm{O}$ enhanced by 3.65

$\mathrm{CH}_{4}$ enhanced by 2.00

Ar enhanced by 0.38

$\begin{array}{lccl}2.23 \times 10^{14} & 0.0 & 48,350.0 & {[74]} \\ 3.57 \times 10^{26} & -2.6 & 62,845.0 & {[\overline{83}]} \\ 3.91 \times 10^{9} & 1.6 & 13,394.6 & {[\overline{62}]} \\ 2.03 \times 10^{4} & 2.6 & 2,507.7 & {[62]} \\ 5.07 \times 10^{3} & 2.6 & 2,507.7 & {[\overline{62}]} \\ 1.87 \times 10^{17} & -1.0 & 8,560.5 & {[6]}\end{array}$

$\mathrm{H}_{2}$ enhanced by 2.00

$\mathrm{H}_{2} \mathrm{O}$ enhanced by 6.00

$\mathrm{CH}_{4}$ enhanced by 2.00

$\mathrm{CO}, \mathrm{CO}^{+}$enhanced by 1.50

$\mathrm{CO}_{2}$ enhanced by 2.00

Ar enhanced by 0.38

$1.34 \times 10^{13}$

$9.00 \times 10^{11}$

$2.50 \times 10^{13}$

$1.00 \times 10^{13}$

$1.30 \times 10^{7}$

$1.50 \times 10^{14}$

$3.00 \times 10^{12}$

$2.5 \times 10^{34}$

$1.60 \times 10^{14}$

$2.0 \times 10^{13}$

$3.36 \times 10^{13}$

$1.0 \times 10^{12}$

$7.00 \times 10^{2}$

$\mathrm{N}, \mathrm{N}^{+}$enhanced by 4.28

$\mathrm{O}, \mathrm{O}^{+}$enhanced by 4.28

$\mathrm{C}, \mathrm{C}^{+}$enhanced by 4.28

$\mathrm{H}, \mathrm{H}^{+}$enhanced by 4.28

$7.00 \times 10^{24}$

$6.40 \times 10^{17}$

$9.9 \times 10^{12}$

$5.40 \times 10^{13}$

$6.30 \times 10^{16}$

$2.00 \times 10^{13}$

$3.80 \times 10^{18}$

$2.35 \times 10^{13}$

$2.00 \times 10^{12}$

$2.50 \times 10^{12}$

$1.00 \times 10^{13}$

$2.00 \times 10^{13}$

$1.80 \times 10^{14}$

$2.16 \times 10^{13}$

$4.00 \times 10^{13}$

$4.61 \times 10^{5}$ $\begin{array}{ll}-0.9 & 0.0\end{array}$

[62]

$\begin{array}{lcl}-1.2 & 0.0 & {[\underline{62}]} \\ -1.2 & 0.0 & {[\overline{62}]} \\ -1.2 & 0.0 & {[\overline{62}]} \\ -1.2 & 0.0 & {[\overline{62}]} \\ -0.8 & 0.0 & {[\underline{62}]} \\ -0.7 & 8.581 .1 & {[\overline{62}]} \\ -2.0 & 0.0 & {[\underline{62}]}\end{array}$

$\begin{array}{ccc}n & T_{a}, \mathrm{~K} & \text { Reference } \\ 0.0 & 0.0 & {[\overline{662}]} \\ 0.0 & 537.8 & {[\overline{62}]} \\ 0.0 & 337.9 & {[\overline{62}]} \\ 0.0 & 1,068.0 & {[\overline{62}]} \\ 0.5 & 74,459.0 & {[\overline{82}]} \\ -1.3 & 372.6 & {[\overline{62}]}\end{array}$

62

$\begin{array}{ccc}0.0 & 201.4 & {[\underline{62}]} \\ 0.7 & 332.4 & {[\overline{62}]} \\ 0.0 & 0.0 & {[\overline{62}]} \\ 0.0 & 6,546.2 & {[\overline{62}]} \\ 1.9 & -478.4 & {[\overline{62}]} \\ 0.0 & 11,883.9 & {[\underline{62}]} \\ 0.0 & 5,690.2 & {[\overline{62}]} \\ -3.82 & 168,600.0 & {[\overline{10}]} \\ 0.0 & 12,650.0 & {[\overline{66}]} \\ 0.00 & 67,500.0 & {[\overline{22}]} \\ 0.0 & 193.9 & {[\overline{62}]} \\ 0.50 & 12,200.0 & {[\underline{22}]} \\ -1.6 & 113,200.0 & {[\overline{10}]}\end{array}$

$\begin{array}{ccc}-1.6 & 113,200.0 & {[\underline{10}]} \\ -1.0 & 38,370.0 & {[\overline{10}]} \\ 0.00 & 40,700 . & {[\overline{22}]} \\ 0.0 & 0.0 & {[\overline{62}]} \\ -0.5 & 24,000.0 & {[\overline{39}]} \\ 0.0 & 0.0 & {[\overline{62}]} \\ -2.0 & 402.8 & {[\overline{62}]} \\ 0.0 & 0.0 & {[\overline{62}]} \\ 0.00 & 10,071.11 & {[\overline{62}]} \\ 0.0 & 0.0 & {[\overline{62}]} \\ 0.0 & 7226.0 & {[\underline{62}]} \\ 0.0 & 6974.2 & {[\overline{62}]} \\ 0.0 & 37,600.0 & {[\overline{84}]} \\ -0.2 & 0.0 & {[\underline{62}]} \\ 0.0 & 0.0 & {[\overline{62}]} \\ 2.0 & 3,273.1 & {[\underline{62}]}\end{array}$


Table 11 (Continued.)

\begin{tabular}{|c|c|c|c|c|c|}
\hline No. & Reaction & $A, \mathrm{~mol} /(\mathrm{cm} \cdot \mathrm{s})$ & $n$ & $T_{a}, \mathrm{~K}$ & References \\
\hline 114 & $\mathrm{NH}+\mathrm{O}_{2} \rightleftharpoons \mathrm{NO}+\mathrm{OH}$ & $1.28 \times 10^{6}$ & 1.5 & 50.4 & {$[62]$} \\
\hline 115 & $\mathrm{NH}+\mathrm{OH} \rightleftharpoons \mathrm{HNO}+\mathrm{H}$ & $2.00 \times 10^{13}$ & 0.0 & 0.0 & {$[\overline{62}]$} \\
\hline 116 & $\mathrm{NH}+\mathrm{OH} \rightleftharpoons \mathrm{N}+\mathrm{H}_{2} \mathrm{O}$ & $2.00 \times 10^{9}$ & 1.2 & 0.0 & [62] \\
\hline 117 & $\mathrm{NO}+\mathrm{M} \rightleftharpoons \mathrm{N}+\mathrm{O}+\mathrm{M}$ & $5.00 \times 10^{15}$ & 0.0 & $75,500.0$ & {$[\overline{39}]$} \\
\hline
\end{tabular}

$\mathrm{C}^{+}$enhanced by 20.0

$\mathrm{N}, \mathrm{N}^{+}$enhanced by 20.0

$\mathrm{O}, \mathrm{O}^{+}$enhanced by 20.0

$\mathrm{H}, \mathrm{H}^{+}$enhanced by 20.0

$\begin{array}{lccl}8.40 \times 10^{12} & 0.0 & 19,450.0 & {[\overline{10}]} \\ 1.0 \times 10^{13} & 0.00 & 23,200.0 & {[\overline{39}]} \\ 7.20 \times 10^{13} & 0.0 & 35,500.0 & {[\overline{22}]} \\ 3.4 \times 10^{13} & 0.00 & 12,800.0 & {[\overline{39}]} \\ 1.0 \times 10^{12} & 0.50 & 77,200.0 & {[\overline{22}]} \\ 7.2 \times 10^{12} & 0.29 & 48,600.0 & {[\overline{39}]} \\ 2.4 \times 10^{13} & 0.41 & 32,600.0 & {[\overline{[22}]} \\ 5.00 \times 10^{13} & 0.0 & 0.0 & {[\overline{62}]} \\ 6.94 \times 10^{6} & 2.0 & 956.8 & {[\overline{62}]} \\ 4.60 \times 10^{19} & -1.4 & 14,577.9 & {[\overline{62}]} \\ 5.70 \times 10^{13} & 0.0 & 0.0 & {[\overline{62}]} \\ 8.00 \times 10^{13} & 0.0 & 0.0 & {[\overline{62}]} \\ 3.37 \times 10^{13} & 0.0 & 0.0 & {[\overline{62}]} \\ 1.02 \times 10^{9} & 1.5 & 4,330.6 & {[\overline{62}]} \\ 3.9 \times 10^{33} & -3.78 & 158,500.0 & {[\overline{39}]} \\ 5.00 \times 10^{17} & -1.0 & 0.0 & {[\underline{62}]}\end{array}$

$\mathrm{H}_{2}$ enhanced by 2.00

$\mathrm{H}_{2} \mathrm{O}$ enhanced by 6.00

$\mathrm{CH}_{4}$ enhanced by 2.00

$\mathrm{CO}, \mathrm{CO}^{+}$enhanced by 1.50

$\mathrm{CO}_{2}$ enhanced by 2.00

$\mathrm{O}+\mathrm{H}_{2} \rightleftharpoons \mathrm{H}+\mathrm{OH}$

$\mathrm{O}+\mathrm{H}_{2} \mathrm{O}_{2} \rightleftharpoons \mathrm{OH}+\mathrm{HO}_{2}$

$\mathrm{O}+\mathrm{HCO} \rightleftharpoons \mathrm{H}+\mathrm{CO}_{2}$

$\mathrm{O}+\mathrm{HCO} \rightleftharpoons \mathrm{OH}+\mathrm{CO}$

$\mathrm{O}+\mathrm{HO}_{2} \rightleftharpoons \mathrm{OH}+\mathrm{O}_{2}$

$\mathrm{O}+\mathrm{N} \rightleftharpoons \mathrm{NO}^{+}+e$

$\mathrm{O}+\mathrm{O} \rightleftharpoons \mathrm{O}_{2}^{+}+e$

$\mathrm{O}^{+}+\mathrm{NO} \rightleftharpoons \mathrm{N}^{+}+\mathrm{O}_{2}$

$\mathrm{O}^{+}+\mathrm{N}_{2} \rightleftharpoons \mathrm{N}_{2}^{+}+\mathrm{O}$

$\mathrm{O}_{2}^{+}+\mathrm{N} \rightleftharpoons \mathrm{N}^{+}+\mathrm{O}_{2}$

$\mathrm{O}_{2}^{+}+\mathrm{O} \rightleftharpoons \mathrm{O}_{2}+\mathrm{O}^{+}$

$\mathrm{O}_{2}+\mathrm{C}^{+} \rightleftharpoons \mathrm{O}_{2}^{+}+\mathrm{C}$

$\mathrm{O}_{2}+\mathrm{M} \rightleftharpoons \mathrm{O}+\mathrm{O}+\mathrm{M}$

\begin{tabular}{lc}
147 & $\mathrm{OH}+\mathrm{C} \rightleftharpoons \mathrm{H}+\mathrm{CO}$ \\
148 & $\mathrm{OH}+\mathrm{C}_{2} \mathrm{H}_{2} \rightleftharpoons \mathrm{CH}_{3}+\mathrm{CO}$ \\
149 & $\mathrm{OH}+\mathrm{CH} \rightleftharpoons \mathrm{H}+\mathrm{HCO}$ \\
150 & $\mathrm{OH}+\mathrm{CH}_{2} \rightleftharpoons \mathrm{CH}+\mathrm{H}_{2} \mathrm{O}$ \\
151 & $\mathrm{OH}+\mathrm{CH}_{3} \rightleftharpoons \mathrm{CH}_{2}+\mathrm{H}_{2} \mathrm{O}$ \\
152 & $\mathrm{OH}+\mathrm{CH}_{4} \rightleftharpoons \mathrm{CH}_{3}+\mathrm{H}_{2} \mathrm{O}$ \\
153 & $\mathrm{OH}+\mathrm{CO} \rightleftharpoons \mathrm{H}+\mathrm{CO}_{2}$ \\
154 & $\mathrm{OH}+\mathrm{C}_{2} \mathrm{H}_{2} \rightleftharpoons \mathrm{C}_{2} \mathrm{H}+\mathrm{H}_{2} \mathrm{O}$ \\
155 & $\mathrm{OH}+\mathrm{H}_{2} \rightleftharpoons \mathrm{H}+\mathrm{H}_{2} \mathrm{O}$ \\
156 & $\mathrm{OH}+\mathrm{H}_{2} \mathrm{O}_{2} \rightleftharpoons \mathrm{HO}_{2}+\mathrm{H}_{2} \mathrm{O}$ \\
157 & $\mathrm{OH}+\mathrm{HCO} \rightleftharpoons \mathrm{H}_{2} \mathrm{O}+\mathrm{CO}$ \\
158 & $\mathrm{OH}+\mathrm{HO}_{2} \rightleftharpoons \mathrm{O}_{2}+\mathrm{H}_{2} \mathrm{O}$ \\
\hline
\end{tabular}

Ar enhanced by 0.7

$9.63 \times 10^{6}$

$3.00 \times 10^{13}$

$3.00 \times 10^{13}$

$2.00 \times 10^{13}$

$5.30 \times 10^{12}$

$1.1 \times 10^{13}$

$1.4 \times 10^{5}$

$9.1 \times 10^{11}$

$8.70 \times 10^{13}$

$4.0 \times 10^{12}$

$1.0 \times 10^{13}$

$2.00 \times 10^{21}$

$\mathrm{N}, \mathrm{N}^{+}$enhanced by 5.00

$\begin{array}{ccc}2.7 & 3,152.3 & {[\underline{62}]} \\ 2.0 & 2,014.2 & {[\overline{62}]} \\ 0.0 & 0.0 & {[\overline{62}]} \\ 0.0 & 0.0 & {[\overline{62}]} \\ 0.0 & 0.0 & {[\overline{62}]} \\ 0.0 & 31,900.0 & {[\overline{39}]} \\ 0.00 & 80,600.0 & {[\overline{\underline{22}}]} \\ 1.90 & 15,300.0 & {[\overline{\underline{22}}]} \\ 0.36 & 22,800.0 & {[\overline{22}]} \\ 0.1 & 28,600.0 & {[\overline{22}]} \\ -0.09 & 18,000.0 & {[\overline{399}]} \\ 0.00 & 9,400.0 & {[\overline{39}]} \\ -1.5 & 59,500.0 & {[\underline{10}]}\end{array}$

$\mathrm{O}, \mathrm{O}^{+}$enhanced by 5.00

$\mathrm{H}, \mathrm{H}^{+}$enhanced by 5.00

$\mathrm{C}, \mathrm{C}^{+}$enhanced by 5.00

$5.00 \times 10^{13}$

$4.83 \times 10^{-4}$

$3.00 \times 10^{13}$

$1.13 \times 10^{7}$

$5.60 \times 10^{7}$

$1.37 \times 10^{6}$

$4.76 \times 10^{7}$

$3.37 \times 10^{7}$

$2.16 \times 10^{8}$

$2.00 \times 10^{12}$

$5.00 \times 10^{13}$

$1.45 \times 10^{13}$

\begin{tabular}{ccc}
0.0 & 0.0 & {$[62]$} \\
4.0 & $-1,007.1$ & {$[\overline{62}]$} \\
0.0 & 0.0 & {$[\overline{62}]$} \\
2.0 & $1,510.7$ & {$[\overline{62}]$} \\
1.6 & $2,729.3$ & {$[\overline{62}]$} \\
2.2 & $1,350.0$ & {$[\overline{85}]$} \\
1.2 & 35.2 & {$[\overline{62}]$} \\
2.00 & $7,049.8$ & {$[\overline{62}]$} \\
1.5 & $1,727.2$ & {$[\overline{62}]$} \\
0.0 & 215.0 & {$[\overline{62}]$} \\
0.0 & 0.0 & {$[\overline{62}]$} \\
0.0 & -251.8 & {$[\underline{62}]$} \\
\hline
\end{tabular}

range of temperature and pressure necessary for hypersonic re-entry flows. This specific case is especially important, since $\mathrm{CN}$ can contribute significantly to the radiative heat flux, as shown in Refs. $[48,69]$. And, the same can be said for some other reactions of the GRI-Mech database that have only been validated over a limited temperature range.

The resulting extended model, presented in Supplementary Table $\mathrm{S} 1$, consists of 240 reactions.

\section{Experimental Comparisons}

To validate the proposed extensive model, multiple zerodimensional simulations are performed using the CHEMKIN [54] package, and the results are compared to available experimental data in Fig. 8. The selected experiments [66,70-72] are representative of typical ablative boundary-layer hypersonic re-entry conditions. The agreement between the model and the experimental data is remarkable and expected, since some of these experiments were employed in the validation and calculation of kinetic rates incorporated in the model.

The discrepancy observed in some of the graphs (Figs. $8 \mathrm{~b}, 8 \mathrm{c}$, and $8 \mathrm{f}$, in particular) is caused by the choice of a different reaction rate than the one obtained from the experimental data. As shown in the Sec. IV.B (Fig. 7), changing one kinetic rate can have a nontrivial impact on the concentration of the species over time. A detailed explanation of this is presented in Ref. [13]. The results presented 
here, although not perfect (with some errors as high as 100\%), are still considered to be in good agreement with experimental data.

\section{Reduced Kinetic Model}

\section{A. Species and Reactions Selection}

Following the methodology developed in Ref. [13] for the Titan atmospheric entries, the extensive model is simplified to a reduced model based on a sensitivity analysis obtained using the software SENKIN, which is part of the CHEMKIN package [54]. SENKIN performs a non-linear sensitivity analysis on the rate coefficients and outputs the results in the form of a normalized maximum sensitivity parameter $S$. For each reaction $r, S$ is computed over time using

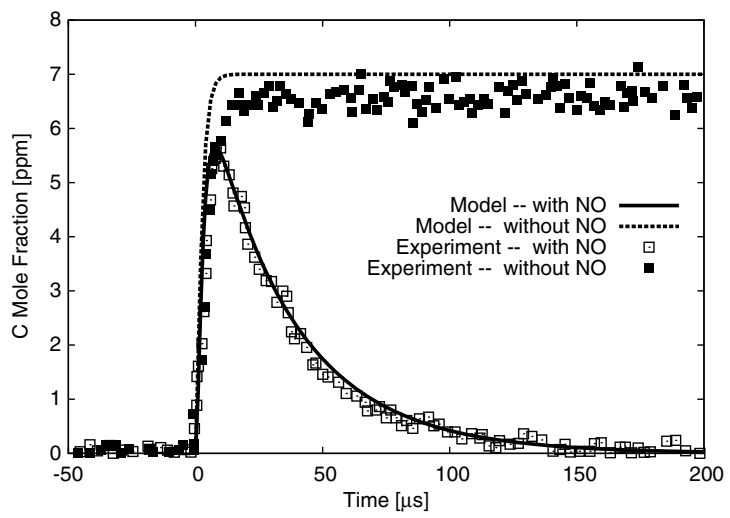

a) Comparison to the experiment of Ref. [70]: $T=2864 \mathrm{~K}$, $p=1.00 \mathrm{~atm}$, and $7 \mathrm{ppm}$ of $\mathrm{C}_{3} \mathrm{O}_{2}$, and $147 \mathrm{ppm}$ of $\mathrm{NO}$ in argon

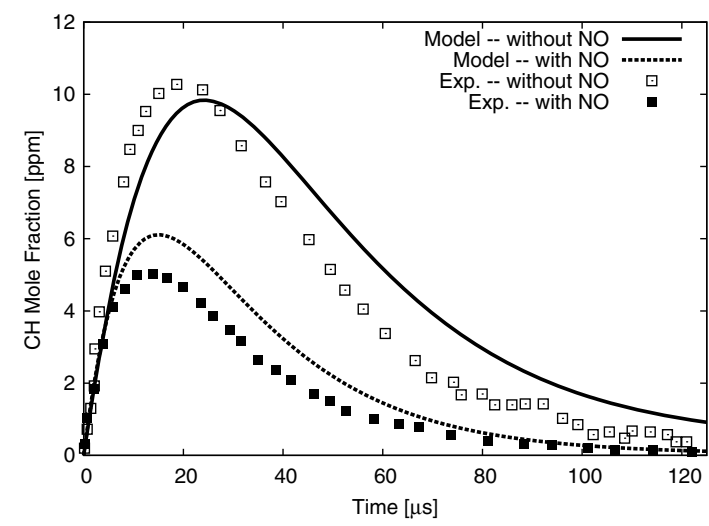

c) Comparison to the experiment of Ref. [70]: $T=3287 \mathrm{~K}$, $p=0.67 \mathrm{~atm}$, and $20 \mathrm{ppm}$ of $\mathrm{C}_{2} \mathrm{H}_{6}$, and $300 \mathrm{ppm}$ of $\mathrm{NO}$ in argon

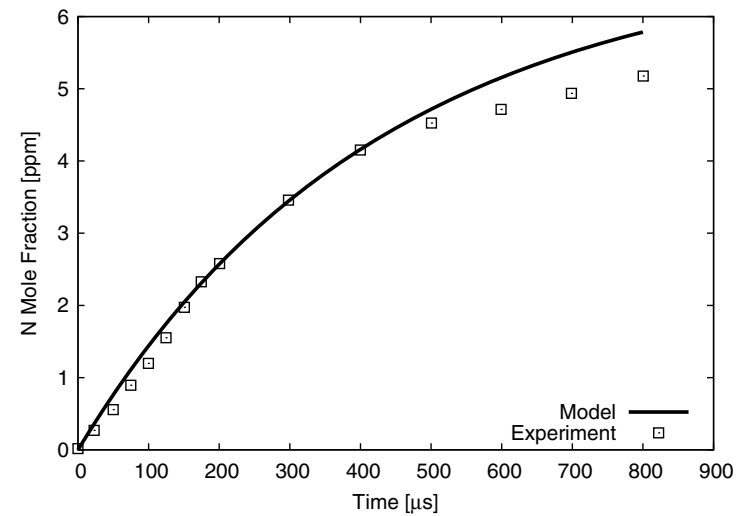

e) Comparison to the experiment of Ref. [71]: $T=5290 \mathrm{~K}$, $p=1.88 \mathrm{~atm}$, and $5 \mathrm{ppm}$ of $\mathrm{C}_{2} \mathrm{~N}_{2}$ in argon

$$
S_{t, r}=\frac{k_{r}}{X_{\max }} \frac{\partial X_{t}}{\partial k_{r}}
$$

where $X_{t}$ represents the parameter on which the sensitivity analysis has been performed at time $t$, and $k_{r}$ is the kinetic rate of reaction $r . X_{\max }$ is chosen as the maximum value of $X_{t}$ over the simulated time. The parameters deemed relevant for ablating Earth entry are the temperature and the number density of $\mathrm{CN}, \mathrm{CO}, \mathrm{H}_{2} \mathrm{O}$, and $\mathrm{OH}$.

The parameter space covered by the sensitivity analysis consists of a range of temperatures, pressures, and species mass fraction as follows: 1) temperatures of $700-6000 \mathrm{~K}$; 2) pressures of $1 \times 10^{-4}-0.5$ atm; and 3) species mass fraction as listed in Table 9 .

The lower bound for the temperature is chosen to be $700 \mathrm{~K}$, a temperature comparable to the onset temperature of pyrolysis for

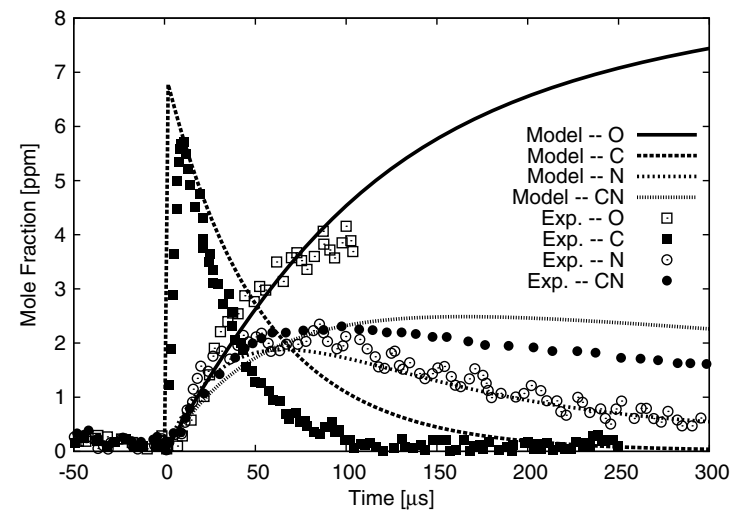

b) Comparison to the experiment of Ref. [70]: $T=3620 \mathrm{~K}$, $p=0.80 \mathrm{~atm}$, and $7 \mathrm{ppm}$ of $\mathrm{C}_{3} \mathrm{O}_{2}$, and $147 \mathrm{ppm}$ of $\mathrm{NO}$ in argon

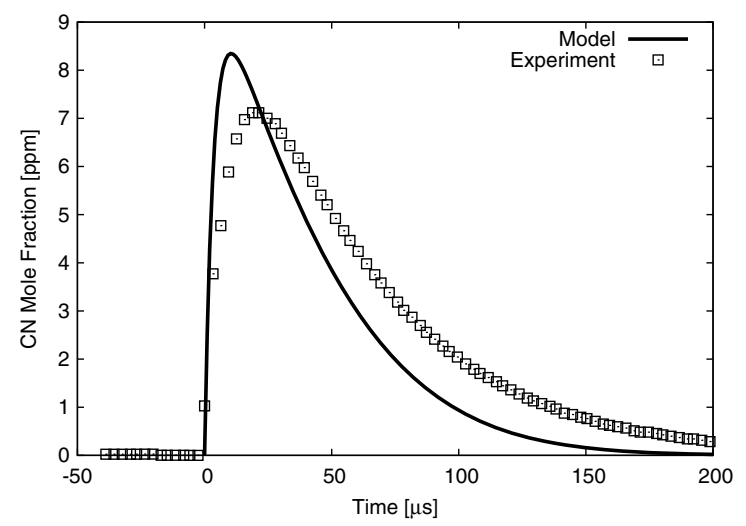

d) Comparison to the experiment of Ref. [66]: $T=3470 \mathrm{~K}$, $p=0.835 \mathrm{~atm}$, and $5 \mathrm{ppm}$ of $\mathrm{C}_{2} \mathrm{~N}_{2}$, and $515 \mathrm{ppm}$ of $\mathrm{O}_{2}$ in argon

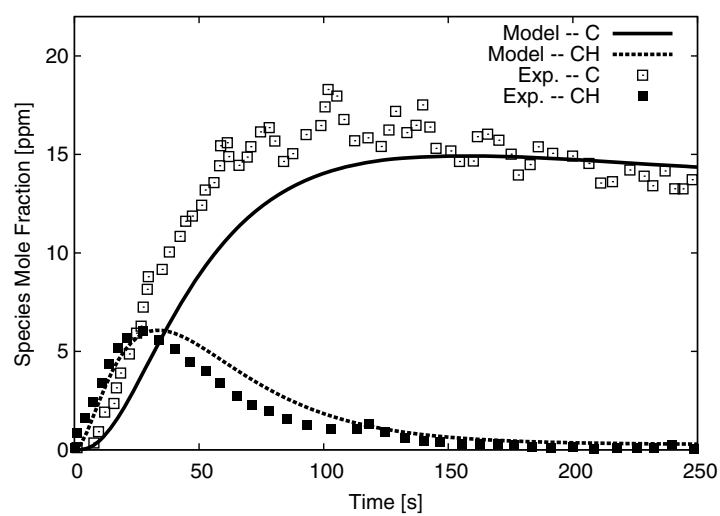

f) Comparison to the experiment of Ref. [72]: $T=3100 \mathrm{~K}$, $p=0.89 \mathrm{~atm}$, and $30 \mathrm{ppm}$ of $\mathrm{CH}_{4}$ in argon

Fig. 8 Validation of the extensive model by comparing predicted mole fractions for selected chemical species against experimental data. 


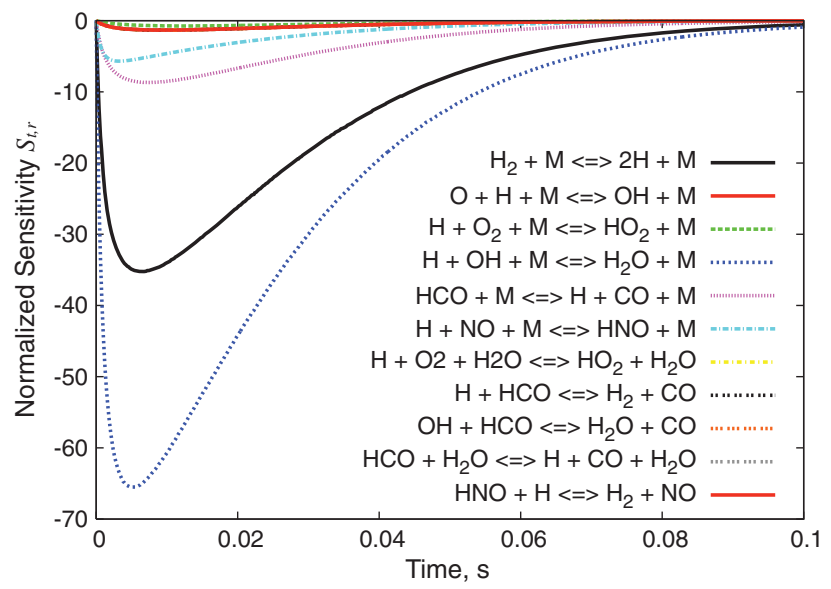

Fig. 9 Temperature sensitivity analysis for the extensive model.

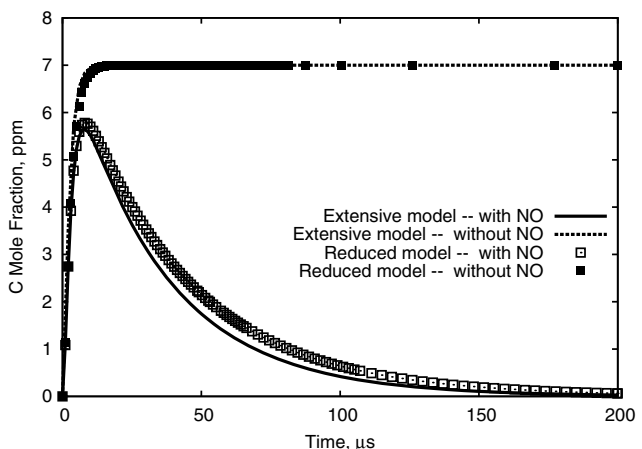

a) Comparison using a test case from Ref. [70]: $T=2864$ $\mathrm{K}, p=1.00 \mathrm{~atm}$, and $7 \mathrm{ppm}$ of $\mathrm{C}_{3} \mathrm{O}_{2}$, and $147 \mathrm{ppm}$ of $\mathrm{NO}$ in argon

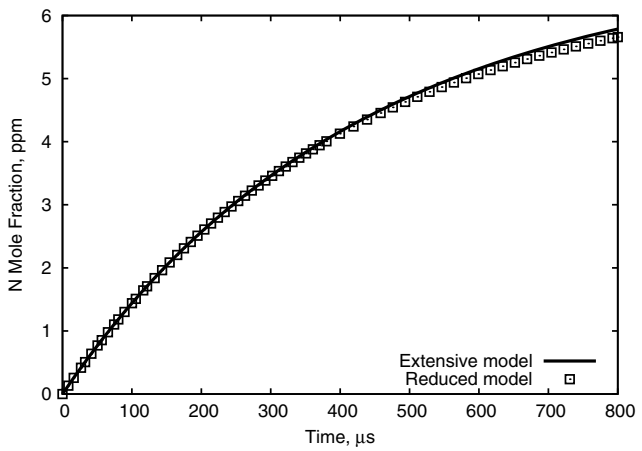

c) Comparison using a test case from Ref. [71]: $T=5290$ $\mathrm{K}, p=1.88 \mathrm{~atm}$, and $5 \mathrm{ppm}$ of $\mathrm{C}_{2} \mathrm{H}_{2}$ in argon
PICA in air $(560 \mathrm{~K})$ or argon $(650 \mathrm{~K})$, as determined by thermogravimetric analysis (TGA). The upper bound for the temperature is set to the maximum value of ablating gases in the boundary layer, i.e., $6000 \mathrm{~K}$. The pressure limits are selected based on extreme limits identified in typical re-entry trajectories (partially shown in Fig. 6).

Figure $\underline{9}$ shows the temperature sensitivity $S_{t, r}$ of the extensive model for an initial composition corresponding to the Stardust reentry equilibrium wall condition at $T=3250 \mathrm{~K}$ and $P=0.5 \mathrm{~atm}$; only the reactions that have a sensitivity of more than $1 \%$ of the maximum sensitivity are shown.

The reduced model contains 38 species, and it is built according to the following process:

1) The results of the sensitivity analysis are used to identify the species that have molar concentrations of more than $1 \%$. These are

$$
\begin{gathered}
\mathrm{C}_{2} \mathrm{H}, \mathrm{C}_{2} \mathrm{H}_{2}, \mathrm{C}_{3}, \mathrm{CH}_{3}, \mathrm{CH}_{4}, \mathrm{CO}, \mathrm{CO}_{2}, \mathrm{H}, \mathrm{H}_{2}, \mathrm{H}_{2} \mathrm{O}, \\
\mathrm{HCN}, \mathrm{N}, \mathrm{N}_{2}, \mathrm{NO}, \mathrm{O}, \mathrm{O}_{2}, \mathrm{OH}
\end{gathered}
$$

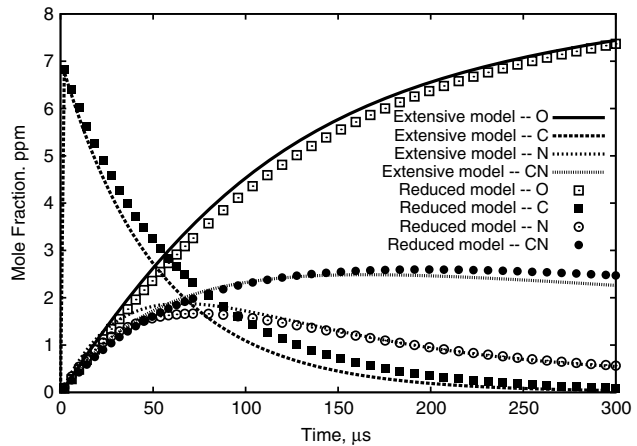

b) Comparison using a test case from Ref. [70]: $T=3620$ $\mathrm{K}, p=0.80 \mathrm{~atm}$, and $7 \mathrm{ppm}$ of $\mathrm{C}_{3} \mathrm{O}_{2}$, and $147 \mathrm{ppm}$ of $\mathrm{NO}$ in argon

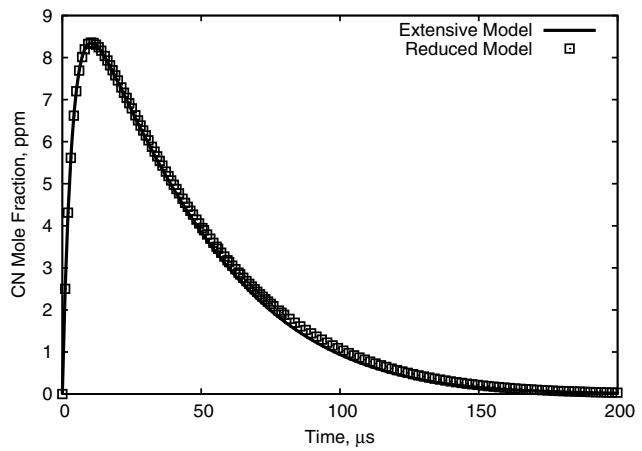

d) Comparison using a test case from Ref. [66]: $T=3470$ $\mathrm{K}, p=0.835 \mathrm{~atm}$, and $5 \mathrm{ppm}$ of $\mathrm{C}_{2} \mathrm{~N}_{2}$ and $515 \mathrm{ppm}$ of $\mathrm{O}_{2}$ in argon

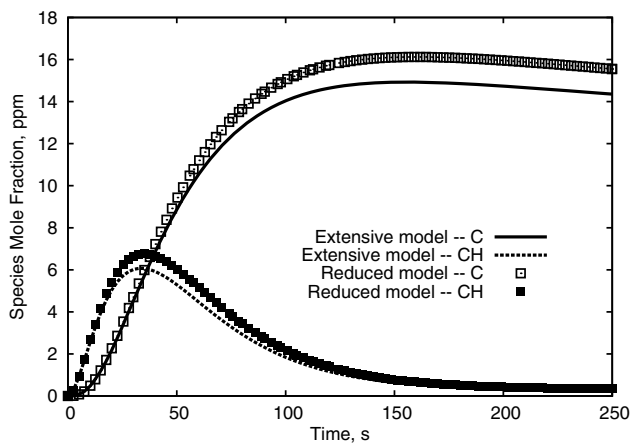

e) Comparison using a test case from Ref. [72]: $T=3100 \mathrm{~K}$, $p=0.89 \mathrm{~atm}$, and $30 \mathrm{ppm}$ of $\mathrm{CH}_{4}$ in argon

Fig. 10 Comparison of extensive baseline and reduced models for phenolic-based carbon ablator decomposition in atmospheric air. 


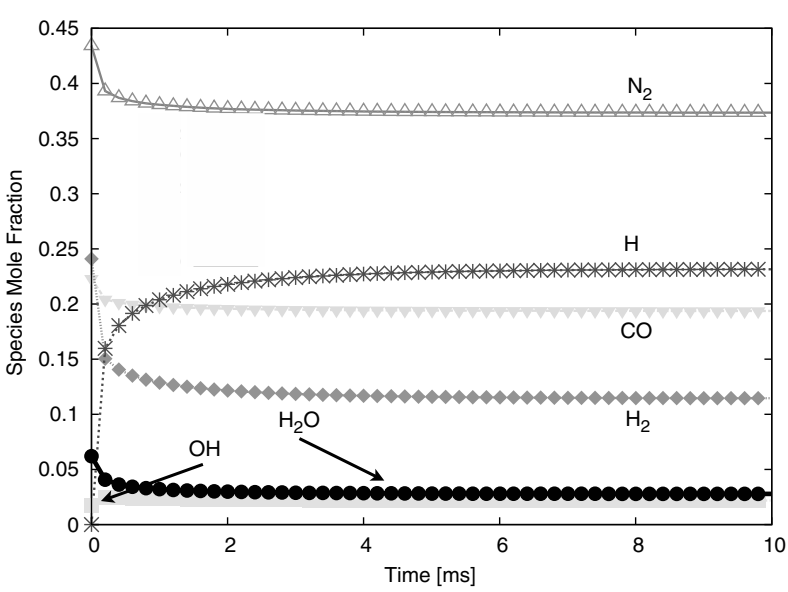

a) High-concentration species

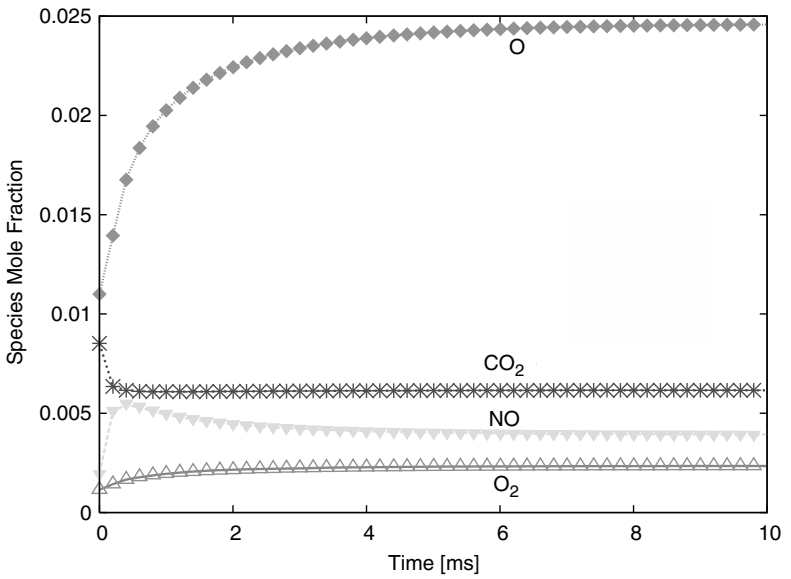

b) Midconcentration species

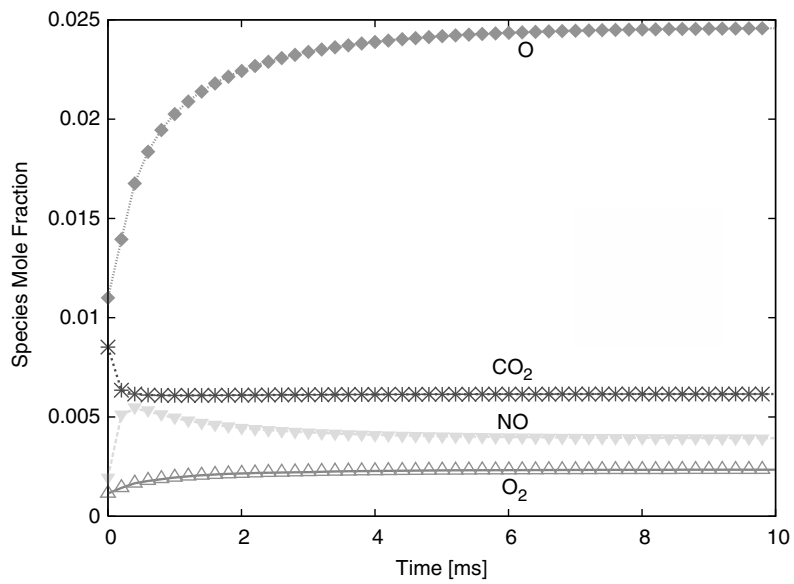

c) Low-concentration species

Fig. 11 Comparison of the extensive and the reduced models for trajectory point $12(T=5000 \mathrm{~K}$ and $p=0.01$ atm $)$.

2) The ionized air species also need to be kept because of their presence in the shock layer (the thermodynamic conditions of the shock layer are not part of the sensitivity analysis), as well as their possible interaction with boundary-layer species. Therefore, the following are also kept:

$$
\mathrm{N}_{2}^{+}, \mathrm{N}^{+}, \mathrm{O}^{+}, \mathrm{NO}^{+}, \mathrm{O}_{2}^{+}, \mathrm{CO}^{+}, \mathrm{C}^{+}, \mathrm{H}^{+} \mathrm{e}^{-}
$$

3) As mentioned earlier, some molecules do not exist in significant concentration, but they allow important, if not crucial, reactions to take place, and therefore need to be present in the models. The species that are deemed important are

$$
\mathrm{CH}, \mathrm{CH}_{2}, \mathrm{C}, \mathrm{C}_{2}, \mathrm{NCO}, \mathrm{NH}, \mathrm{HNO}, \mathrm{HCO}, \mathrm{H}_{2} \mathrm{O}_{2}, \mathrm{HO}_{2}
$$

4) Finally, because of their radiative properties, the following species are also included in the reduced model:

\section{$\mathrm{CN}, \mathrm{CN}^{+}$}

The same sensitive analysis is employed to reduce the number of chemical reactions in the model: all reactions with less than $1 \%$ contribution to the total sensitivity are excluded. The final set contains the 152 reactions listed in Table 11 , taken from Refs. $[10,13,22,39,62,65-68,72-85]$. In this table, the kinetic rates are expressed according to the modified Arrhenius format described by Eq. (). .

With this new, proposed model, all the shortcomings of the previously published models identified in the first part of this work have been addressed. The new model includes all the species and all the reactions contained in the legacy model, but it also includes additional ones that are shown or assumed to be important. As for the kinetics rates, they have been updated using recently published research, with the majority of them coming from a coherent, validated kinetic set.

\section{B. Comparison}

Figure 10 shows the comparison of the reduced model against the experimental data set used to validate the extensive (baseline) model. The deviations are, at most, $10 \%$, and thus considered to be in good agreement. Comparison of the extensive baseline model and the reduced model for the ablating gas composition corresponding to trajectory point 12 in Table 9 is shown in Fig. 11 (initial temperature is set to $5000 \mathrm{~K}$ and pressure at $0.01 \mathrm{~atm}$ ). In this case, excellent agreement in terms of species concentrations is achieved.

\section{Conclusions}

To improve heat and ablation modeling on hypersonic re-entry vehicles, a comprehensive study of the chemistry model for carbon base ablative thermal protection systems in atmospheric air was presented.

Three published carbon-phenolic-in-air chemistry models were identified and analyzed. In all cases, it was shown that key species and reactions were missing from the models. Using the three models in a hypersonic aerothermodynamic CFD code, typical re-entry results were obtained for a trajectory point of the Stardust re-entry vehicle. These results showed significant discrepancies in the boundary-layer composition. The convective heat flux, as well as the radiative heat flux, also proved to be affected by the choice of model.

A new chemistry model was developed by carefully selecting and reducing a comprehensive set of species and reaction rates. The 
species and reaction rates were chosen in regard to what was deemed important in all the regions of the flow field. Most of the reaction rates were taken from a validated combustion database, although some of them were replaced with more appropriate values, based on hypersonic re-entry conditions. It was noted that certain rates used in the model would still benefit from further research to ensure that they are valid at higher (and sometimes lower) temperatures. The baseline model was validated using a series of experimental results.

The model was then reduced to a more manageable number of species and reactions using zero-dimensional and one-dimensional sensitivity analyses. This reduced model was then compared to the extensive baseline model, to insure its validity. The final model, comprising 38 species and 158 reactions, was considered to be complete but small enough to be used in hypersonic aerothermodynamic CFD simulations.

\section{Acknowledgments}

Financial support for this work was provided in part by the Constellation University Institutes Program, under NASA grant NCC3989, as well as through the NASA Prime Contract NNA04BC25C to the Eloret Corporation. Additional funding was provided by the NASA Kentucky EPSCoR Award NNX10AV39A and NASA RA Award NNX13AN04A. The authors would also like to thank T. Gökçen and C. Jonhston for numerous insightful discussions, as well as J. Lachaud, T. Magin, and G. Blanquart for clarifications on chemistry theory. Many thanks are also extended to M. Barnhardt, D. Hash, N. Mansour, and C. Dateo for managing this project. Finally, the authors would like to thank the Michigan Institute for Plasma Science and Engineering andM. Kushner for providing some of the computational resources needed for this project.

\section{References}

[1] Martin, A., and Boyd, I. D., "Strongly Coupled Computation of Material Response and Nonequilibrium Flow for Hypersonic Ablation," Journal of Spacecraft and Rockets, Oct. 2014. doi:10.2514/1.A32847

-[2] Martin, A., and Boyd, I. D., "Non-Darcian Behavior of Pyrolysis Gas in a Thermal Protection System," Journal of Thermophysics and Heat Transfer, Vol. 24, No. 1, 2010, pp. 60-68. doi: $10.2514 / 1.44103$

-[3] Suzuki, T., Sawada, K., Yamada, T., and Inatani, Y., "Experimental and Numerical Study of Pyrolysis Gas Pressure in Ablating Test Piece," Journal of Thermophysics and Heat Transfer, Vol. 19, No. 3, 2005, pp. 266-272. doi:10.2514/1.12211

[4] Dec, J. A., and Braun, R. D., "An Approximate Ablative Thermal Protection System Sizing Tool for Entry System Design," AIAA Paper 2006-0780, 2006.

doi: $10.2514 / 6.2006-780$

[5] Ayasoufi, A., Rahmani, R. K., Cheng, G., Koomullil, R., and Neroorkar, K., "Numerical Simulation of Ablation for Reentry Vehicles," AIAA Paper 2006-2908, 2006. doi:10.2514/6.2006-2908

[6] Amar, A. J., Blackwell, B. F., and Edward, J. R., "One-Dimensional Ablation with Pyrolysis Gas Flow Using a Full Newton's Method and Finite Control Volume Procedure," AIAA Paper 2007-4535, 2007. doi: $10.2514 / 1.29610$

- [7] Milos, F. S., and Chen, Y.-K., "Two-Dimensional Ablation, Thermal Response, and Sizing Program for Pyrolyzing Ablators," Journal of Spacecraft and Rockets, Vol. 46, No. 6, 2009, pp. 1089-1099. doi:10.2514/1.36575

[8] Venkatachari, B. S., Cheng, G. C., Koomullil, R. P., and Ayasoufi, A., "Computational Tools for Re-Entry Aerothermodynamics, Part II: Surface Ablation," AIAA Paper 2008-1218, 2008. doi: $10.2514 / 6.2008-1218$

[9] Martin, A., and Boyd, I. D., "Simulation of Pyrolysis Gas Within a Thermal Protection System," AIAA Paper 2008-3805, 2008. doi:10.2514/6.2008-3805

[10] Park, C., Jaffe, R. L., and Partridge, H., "Chemical-Kinetic Parameters of Hyperbolic Earth Entry," Journal of Thermophysics and Heat Transfer, Vol. 15, No. 1, 2001, pp. 76-90. doi: $10.2514 / 2.6582$

[11] Suzuki, K., Kubota, H., Fujita, K., and Abe, T., "Chemical NonEquilibrium Ablation Analysis of MUSES-C Super-Orbital Reentry
Capsule," AIAA Paper 1997-2481, 1997.

doi:10.2514/6.1997-2481

[12] Olynick, D. R., Chen, Y.-K., and Tauber, M. E., "Aerothermodynamics of the Stardust Sample Return Capsule," Journal of Spacecraft and Rockets, Vol. 36, No. 3, 1999, pp. 442-462.

doi: $10.2514 / 2.3466$

[13] Gökçen, T., " $\mathrm{N}_{2}-\mathrm{CH}_{4}-\mathrm{Ar}$ Chemical Kinetic Model for Simulations of Titan Atmospheric Entry," Journal of Thermophysics and Heat Transfer, Vol. 21, No. 1, 2007, pp. 9-18. doi: $10.2514 / 1.22095$

[14] Martin, A., Scalabrin, L. C., and Boyd, I. D., "High Performance Modeling of an Atmospheric Re-Entry Vehicle," Journal of Physics: Conference Series, Vol. 341, No. 1, 2012, Paper 012002. doi:10.1088/1742-6596/341/1/012002

[15] Nompelis, I., Drayna, T. W., and Candler, G. V., "A Parallel Unstructured Implicit Solver for Hypersonic Reacting Flow Simulation,” AIAA Paper 2005-4867, 2005. doi:10.2514/6.2005-4867

[16] Wright, M. J., Candler, G. V., and Bose, D., "Data-Parallel Line Relaxation Method for the Navier-Stokes Equations," AIAA Journal, Vol. 36, No. 9, 1998, pp. 1603-1609. doi: $10.2514 / 2.586$

[17] Gnoffo, P. A., "Upwind-Biased, Point-implicit Relaxation Strategies for Viscous Hypersonic Flows," AIAA Paper 1989-1972, 1989. doi:10.2514/6.1989-1972

[18] Holman, T. D., and Boyd, I. D., "Effects of Continuum Breakdown on the Surface Properties of a Hypersonic Sphere," Journal of Thermophysics and Heat Transfer, Vol. 23, No. 4, Oct.-Dec. 2009, pp. 660-673. doi:10.2514/1.43509

[19] Wilke, C., "A Viscosity Equation for Gas Mixtures," Journal of Chemical Physics, Vol. 18, No. 4, 1950, pp. 517-519. doi:10.1063/1.1747673

[20] Blottner, F. G., Johnson, M., and Ellis, M., "Chemically Reacting Viscous Flow Program for Multi-Component Gas Mixtures," Sandia National Labs TR SC-RR-70-754, Albuquerque, NM, 1971.

[21] Vincenti, W. G., and Kruger, C. H., Introduction to Physical Gas Dynamics, Krieger, Malabar, FL, 1982, p. 21.

[22] Park, C., Nonequilibrium Hypersonic Aerothermodynamics, WileyInterscience, New York, Feb. 1990, pp. 108-111.

[23] Scalabrin, L. C., "Numerical Simulation of Weakly Ionized Hypersonic Flow Over Reentry Capsules," Ph.D. Thesis, Univ. of Michigan, Ann Arbor, MI, 2007.

[24] Steger, J. L., and Warming, R. F., "Flux Vector Splitting for the Inviscid Gasdynamic Equations with Applications to Finite Difference Methods," Journal of Computational Physics, Vol. 40, No. 2, 1981, pp. 263 293. doi:10.1016/0021-9991(81)90210-2

[25] Scalabrin, L. C., and Boyd, I. D., "Development of an Unstructured Navier-Stokes Solver for Hypersonic Nonequilibrium Aerothermodynamics," AIAA Paper 2005-5203, 2005. doi: $10.2514 / 6.2005-5203$

[26] Scalabrin, L. C., and Boyd, I. D., "Numerical Simulation of Weakly Ionized Hypersonic Flow for Reentry Configurations," AIAA Paper 2006-3773, 2006. doi: $10.2514 / 6.2006-3773$

[27] Alkandry, H., Boyd, I. D., Reed, E. M., Codoni, J. R., and McDaniel, J. C., "Interactions of Single-Nozzle Sonic Propulsive Deceleration Jets on Mars Entry Aeroshells," Journal of Spacecraft and Rockets, Vol. 48, No. 4, 2011, pp. 564-572. doi: $10.2514 / 1.52232$

[28] Alkandry, H., Boyd, I. D., Reed, E. M., Codoni, J. R., and McDaniel, J. C., "Aerodynamic Interactions of Reaction-Control-System Jets for Atmospheric Entry Aeroshells," AIAA Journal, Vol. 51, No. 5, 2013, pp. $1105-1118$. doi:10.2514/1.J051943

[29] McDaniel, J. C., Codoni, J. R., Reed, E. M., Alkandry, H., and Boyd, I. D., "Propulsion Deceleration Studies Using Planar Laser-Induced Iodine Fluorescence and Computational Fluid Dynamics," Journal of Spacecraft and Rockets, Vol. 50, No. 4, 2013, pp. 771-780. doi:10.2514/1.A32328

[30] Farbar, E. D., Boyd, I. D., and Martin, A., "Numerical Prediction of Hypersonic Flowfields Including Effects of Electron Translational Nonequilibrium," Journal of Thermophysics and Heat Transfer, Vol. 27, No. 4, 2013, pp. 593-606. doi:10.2514/1.T3963

[31] Scalabrin, L. C., and Boyd, I. D., "Numerical Simulations of the FIRE-II Convective and Radiative Heating Rates," AIAA Paper 2007-4044, 2007. doi:10.2514/6.2007-4044 
[32] Alkandry, H., Farbar, E., and Boyd, I., "Evaluation of Finite-Rate Surface Chemistry Models for Simulation of the Stardust Reentry Capsule," AIAA Paper 2012-2874, 2012. doi: $10.2514 / 6.2012-2874$

[33] Alkandry, H., Boyd, I. D., and Martin, A., "Comparison of Transport Properties for Flowfield Simulations of Ablative Heat Shields," Journal of Thermophysics and Heat Transfer, Vol. 28, No. 4, 2014, pp. 569-582. doi:10.2514/1.T4233

[34] Boyd, I. D., Martin, A., Wiebenga, J. E., and Jenniskens, P., "Hypersonic Flow and Radiation Analysis of the Automated Transfer Vehicle Jules Verne," Journal of Spacecraft and Rockets, Vol. 50, No. 1, 2013, pp. 124-136. doi: $10.2514 / 1 . A 32208$

[35] Martinelli, S., and Ruffin, S., "Validation Process for Blowing and Transpiration-Cooling in DPLR," AIAA Paper 2007-4255, 2007. doi: $10.2514 / 6.2007-4255$

[36] Thompson, R. A., and Gnoffo, P. A., "Implementation of a Blowing Boundary Condition in the LAURA Code," AIAA Paper 2008-1243, 2008. doi:10.2514/6.2008-1243

[37] Martin, A., and Boyd, I. D., "Implicit Implementation of Material Response and Moving Meshes for Hypersonic Re-Entry Ablation," AIAA Paper 2009-0670, 2009. doi: $10.2514 / 6.2009-670$

[38] McBride, B. J., and Gordon, S., "Computer Program for Calculation of Complex Chemical Equilibrium Compositions and Applications II. User's Manual and Program Description," NASA Lewis Research Center TR RP-1311-P2, 1996.

[39] Park, C., Howe, J. T., Jaffe, R. L., and Candler, G. V., "Review of Chemical-Kinetic Problems of Future NASA Missions, II: Mars Entries," Journal of Thermophysics and Heat Transfer, Vol. 8, No. 1, 1994, pp. 9-23. doi: $10.2514 / 3.496$

[40] Baulch, D. L., Drysdale, D. D., and Horne, D. G., "Homogeneous Gas Phase Reactions of the $\mathrm{H}_{2}-\mathrm{O}_{2}$ System," Evaluated Kinetic Data for High Temperature Reactions, Vol. 1, CRC Press, Boca Raton, FL, 1972, p. 433.

[41] Bose, D., and Candler, G. V., "Thermal Rate Constants of the $\mathrm{N}_{2}+\mathrm{O} \rightarrow$ $\mathrm{NO}+\mathrm{N}$ Reaction Using Ab Initio ${ }^{3} \mathrm{~A}$ and ${ }^{3} \mathrm{~A}$ 'Potential Energy Surfaces," Journal of Chemical Physics, Vol. 104, No. 8, 1996, pp. 28252833.

doi:10.1063/1.471106

[42] Bose, D., and Candler, G. V., "Thermal Rate Constants of the $\mathrm{O}_{2}+\mathrm{N} \rightarrow$ $\mathrm{NO}+\mathrm{O}$ Reaction Based on the ${ }^{2} \mathrm{~A}$ and ${ }^{4} \mathrm{~A}$ 'Potential-Energy Surfaces," Journal of Chemical Physics, Vol. 107, No. 16, 1997, pp. 6136-6145. doi: $10.1063 / 1.475132$

[43] Gupta, R. N., Yos, J. M., Thompson, R. A., and Lee, K.-P., "A Review of Reaction Rates and Thermodynamic and Transport Properties for an 11-Species Air Model for Chemical and Thermal Nonequilibrium Calculations to 30000 K," NASA Langley Research Center TR RP$1232,1989$.

[44] Song, D. J., and Lewis, C. H., "Hypersonic Finite-Rate Chemically Reacting Viscous Flows over an Ablating Carbon Surface," Journal of Spacecraft, Vol. 23, No. 1, 1986, pp. 47-54. doi: $10.2514 / 3.25082$

[45] Blottner, F. G., "Prediction of Electron Density in the Boundary Layer on Entry Vehicles with Ablation," The Entry Plasma Sheath and Its Effects on Space Vehicle Electronmagnetic Systems, Vol. 1, NASA Langley Research Center SP-252, Hampton, VA, 1970, pp. 219840.

[46] Heicklen, J., "Gas-Phase Chemistry of Re-Entry." AIAA Journal, Vol. 5, No. 1, 1967, pp. 4-15. doi: $10.2514 / 3.3901$

[47] Westbrook, C. K., Pitz, W. J., and Urtiew, P. A., "Chemical Kinetics of Propane Oxidation in Gaseous Detonations," Dynamics of Shock Waves, Explosions, and Detonations, Progress in Astronautics and Aeronautics, AIAA, New York, 1985, pp. 151-174. doi:10.2514/5.9781600865695.0151.0174

[48] Martin, A., and Boyd, I. D., "Modeling of Heat Transfer Attenuation by Ablative Gases During the Stardust Reentry," Journal of Thermophysics and Heat Transfer (submitted for publication). doi:10.2514/3.T4202

[49] Wilson, J., "Ionization Rates of Air Behind High Speed Shock Waves," Physics of Fluids, Vol. 9, No. 10, 1966, pp. 1913-1921. doi:10.1063/1.1761543

[50] Bhutta, B. A., and Lewis, C. H., "New Technique for Low-to-High Altitude Predictions of Ablative Hypersonic Flow Fields," Journal of Spacecraft and Rockets, Vol. 29, No. 1, 1992, pp. 35-50. doi: $10.2514 / 3.26311$
[51] Sangisvanni, J. J., Barber, T. J., and Syed, S. A., "Role of Hydrogen/Air Chemistry in Nozzle Performances for Hypersonic Propulsion System," Journal of Propulsion and Power, Vol. 9, No. 1, 1993, pp. 134-138. doi: $10.2514 / 3.11495$

[52] Trumble, K. A., Cozmuta, I., Sepka, S., and Jenniskens, P., "Post-Flight Aerothermal Analysis of the Stardust Sample Return Capsule," AIAA Paper 2008-1201, 2008. doi:10.2514/6.2008-1201

[53] Martin, A., Boyd, I. D., Cozmuta, I., and Wright, M. J., "Chemistry Model for Ablating Carbon-Phenolic Material During Atmospheric ReEntry," AIAA Paper 2010-1175, 2010. doi:10.2514/6.2010-1175

[54] Kee, R. J., Rupley, F. M., Miller, J. A., Coltrin, M. E., Grcar, J. F., Meeks, E., Moffat, H. K., Lutz, A. E., Dixon-Lewis, G., Smooke, M. D., Warnatz, J., Evans, G. H., Larson, R. S., Mitchell, R. E., Petzold, L. R., Reynolds, W. C., Caracotsios, M., Stewart, W. E., Glarborg, P., Wang, C., McLellan, C. L., Adigun, O., Houf, W., Chou, C. P., Miller, S. F., Ho, P., Young, P. D., Young, D. J., Hodgson, D. W., Petrova, M. V., and Puduppakkam, K. V., CHEMKIN, Software Package, Release 4.1, Reaction Design, 2006.

[55] Whiting, E. E., Park, C., Liu, Y., Arnold, J. O., and Paterson, J. A., "NEQAIR96, Nonequilibrium and Equilibrium Radiative Transport and Spectra Program: User's Manual," NASA TR RP-1389, Dec. 1996.

[56] Chen, Y.-K., and Milos, F. S., "Ablation and Thermal Response Program for Spacecraft Heatshield Analysis," Journal of Spacecraft and Rockets, Vol. 36, No. 3, 1999, pp. 475-483. doi: $10.2514 / 2.3469$

[57] Kinney, D. J., "Aerothermal Anchoring of CBAero Using High Fidelity CFD," AIAA Paper 2007-0608, 2007. doi:10.2514/6.2007-608

[58] Milos, F. S., and Chen, Y.-K., "Ablation and Thermal Response Property Model Validation for Phenolic Impregnated Carbon Ablator," AIAA Paper 2009-0262, 2009. doi:10.2514/6.2009-262

[59] Milos, F. S., and Chen, Y.-K., "Comprehensive Model for Multicomponent Ablation Thermochemistry," AIAA Paper 1997-0141, 1997. doi:10.2514/6.1997-141

[60] Duff, R. E., and Bauer, S. H., "Equilibrium Composition of the $\mathrm{C} / \mathrm{H}$ System at Elevated Temperatures," Journal of Chemical Physics, Vol. 36, No. 7, 1962, pp. 1754-1767. doi:10.1063/1.1701262

[61] Goos, E., Burcat, A., and Ruscic, B., Extended Third Millenium Ideal Gas Mand Condensed Phase Thermochemical Database for Combustion with Updates from Active Thermochemical Tables [online database], http://garfield.chem.elte.hu/Burcat/THERM.DAT [retrieved April 2009].

[62] Smith, G. P., Golden, D. M., Frenklach, M., Moriarty, N. W., Eiteneer, B., Goldenberg, M., Bowman, C. T., Hanson, R. K., Song, S., Gardiner, W. C., Jr., Lissianski, V. V., and Qin, Z., "GRI-Mech 3.0," 2009, http:// www.me.berkeley.edu/gri_mech/ [retrieved April 2009].

[63] Louge, M. Y., and Hanson, R. K., "Shock Tube Study of Cyanogen Oxidation Kinetics," International Journal of Chemical Kinetics, Vol. 16, No. 3, 1984, pp. 231-250. doi:10.1002/kin.550160306

[64] Mozzhukin, E. V., Burmeister, M., and Roth, P., "High Temperature Dissociation of CN Radicals," Berichte der Bunsengesellschaft für Physikalische Chemie, Vol. 93, No. 1, 1989, pp. 70-75. doi:10.1002/bbpc.19890930114

[65] Lindackers, D., Burmeister, M., and Roth, P., "High-Temperature Kinetics of the Reaction $\mathrm{CN}+\mathrm{CO}_{2}$," Combustion and Flame, Vol. 81, Nos. 3-4, 1990, pp. 251-259. doi:10.1016/0010-2180(90)90023-K

[66] Davidson, D. F., Dean, A. J., Dirosa, M. D., and Hanson, R. K., "Shock Tube Measurements of the Reactions of $\mathrm{CN}$ with $\mathrm{O}$ and $\mathrm{O}_{2}$," International Journal of Chemical Kinetics, Vol. 23, No. 11, 1991, pp. $1035-1050$. doi:10.1002/kin.550231107

[67] Baulch, D. L., Cobos, C. J., Cox, R. A., Esser, C., Frank, P., Just, T., Kerr, J. A., Pilling, M. J., Troe, J., Walker, R. W., and Warnatz, J., "Evaluated Kinetic Data for Combustion Modelling," Journal of Physical and Chemical Reference Data, Vol. 21, No. 3, 1992, pp. 411-734. doi:10.1063/1.555908

[68] Andersson, S., Markovic, N., and Nyman, G., "Computational Studies of the Kinetics of the C $+\mathrm{NO}$ and $\mathrm{O}+\mathrm{CN}$ Reactions," Journal of Physical Chemistry A, Vol. 107, No. 28, 2003, pp. 5439-5447. doi:10.1021/jp0222604

[69] Martin, A., Farbar, E. D., and Boyd, I. D., "Numerical Modeling of the CN Spectral Emission of the Stardust Re-Entry Vehicle," AIAA Paper 
2011-3125, 2011.

doi:10.2514/6.2011-3125

[70] Dean, A. J., Hanson, R. K., and Bowman, C. T., "A Shock Tube Study of Reactions of $\mathrm{C}$ Atoms and $\mathrm{CH}$ with $\mathrm{NO}$ Including Product Channel Measurements," Journal of Chemical Physics, Vol. 95, No. 8, 1991, pp. 3180-3189. doi:10.1021/j100161a042

[71] Mick, H. J., and Roth, P., "High Temperature Thermal Decomposition of $\mathrm{CO}$ and CN," Shock Waves - Proceedings of the 18th International Symposium on Shock Waves, Vol. 2, Springer, New York, 1992, pp. 805-812.

doi:10.1007/978-3-642-77648-9_126

[72] Dean, A. J., and Hanson, R. K., " $\mathrm{CH}$ and C-Atom Time Histories in Dilute Hydrocarbon Pyrolysis: Measurements and Kinetics Calculations," International Journal of Chemical Kinetics, Vol. 24, No. 6, 1992, pp. 517-532. doi:10.1002/kin.550240602

[73] Dean, A. J., Davidson, D. F., and Hanson, R. K., "A Shock Tube Study of Reactions of $\mathrm{C}$ Atoms with $\mathrm{H}_{2}$ and $\mathrm{O}_{2}$ Using Excimer Photolysis of $\mathrm{C}_{3} \mathrm{O}_{2}$ and $\mathrm{C}$ Atom Atomic Resonance Absorption Spectroscopy," Journal of Physical Chemistry, Vol. 95, No. 1, 1991, pp. 183-191. doi:10.1021/j100154a037

[74] Baulch, D. L., Cobos, C. J., Cox, R. A., Frank, P., Hayman, G., Just, T., Kerr, J. A., Murrells, T., Pilling, M. J., Troe, J., Walker, R. W., and Warnatz, J., "Evaluated Kinetic Data for Combustion Modeling. Supplement I," Journal of Physical and Chemical Reference Data, Vol. 23, No. 6, 1994, pp. 847-848. doi: $10.1063 / 1.555953$

[75] Kruse, T., and Roth, P., "Kinetics of $\mathrm{C}_{2}$ Reactions During HighTemperature Pyrolysis of Acetylene," Journal of Physical Chemistry A, Vol. 101, No. 11, 1997, pp. 2138-2146. doi:10.1021/jp963373o

[76] Sommer, T., Kruse, T., and Roth, P., "Perturbation Study on the Reaction of $\mathrm{C}_{2}$ with $\mathrm{N}_{2}$ in High-Temperature $\mathrm{C}_{6} \mathrm{O}+\mathrm{Ar}+\mathrm{N}_{2}$ Mixtures," Journal of Physical Chemistry A, Vol. 101, No. 20, 1997, pp. 3720-3725. doi:10.1021/jp962779y

[77] Dean, A. J., Hanson, R. K., and Bowman, C. T., "High Temperature Shock Tube Study of Reactions of CH and C-Atoms with $\mathrm{N}_{2}$," Symposium (International) on Combustion, Vol. 23, No. 1, 1991, pp. 259-265. doi:10.1016/S0082-0784(06)80268-7
[78] Bauerle, S., Klatt, M., and Wagner, H. G., "Recombination and Decomposition of Methylene Radicals at High Temperatures," Berichte der Bunsengesellschaft für Physikalische Chemie, Vol. 99, No. 6, 1995, pp. 870-879. doi:10.1002/bbpc.19950990612

[79] Bohland, T., Dobe, S., Temps, F., and Wagner, H., "Kinetics of the Reactions Between $\mathrm{CH}_{2}\left(\tilde{X}^{3} \mathrm{~B}_{1}\right)$-Radicals and Saturated Hydrocarbons in the Temperature Range $296 \mathrm{~K} \leq T \leq 707 \mathrm{~K}$," Berichte der Bunsengesellschaft für Physikalische Chemie, Vol. 89, No. 10, 1985, pp. 1110-1116. doi:10.1002/bbpc. 19850891018

[80] Sanders, W., Lin, C., and Lin, M., "On the Importance of the Reaction $\mathrm{CH}_{2}+\mathrm{N}_{2}=\mathrm{HCN}+\mathrm{NH}$ as a Precursor for Prompt NO Formation," Combustion Science and Technology, Vol. 51, Nos. 1-3, 1987, pp. 103108 . doi:10.1080/00102208708960318

[81] Tsang, W., and Hampson, R., "Chemical Kinetic Data Base for Combustion Chemistry, Part I: Methane and Related Compounds," Journal of Physical and Chemical Reference Data, Vol. 15, No. 3, 1986, Paper 1087. doi:10.1063/1.555759

[82] Caridade, P., Rodrigues, S., Sousa, F., and Varandas, A., "Unimolecular and Bimolecular Calculations for $\mathrm{HN}_{2}$, , Journal of Physical Chemistry A, Vol. 109, No. 10, 2005, pp. 2356-2363. doi: $10.1021 / \mathrm{jp} 045102 \mathrm{~g}$

[83] Tsang, W., and Herron, J. T., "Chemical Kinetic Data Base for Propellant Combustion 1. Reactions Involving $\mathrm{NO}, \mathrm{NO}_{2}, \mathrm{HNO}, \mathrm{HNO}_{2}$, $\mathrm{HCN}$ and $\mathrm{N}_{2} \mathrm{O}$," Journal of Physical Chemistry Reference Data, Vol. 20 , No. 4, 1991, pp. 609-663. doi:10.1063/1.555890

[84] Deppe, J., Friedrichs, G., Ibrahim, A., Romming, H.-J., and Wagner, H., "The Thermal Decomposition of NH2 and NH Radicals," Berichte der Bunsengesellschaft für Physikalische Chemie, Vol. 102, No. 10, 1998, pp. 1474-1485. doi:10.1002/bbpc. 199800016

[85] Baulch, D. L., Bowman, C. T., Cobos, C. J., Cox, R. A., Just, T., Kerr, J. A., Pilling, M. J., Stocker, D., Troe, J., Tsang, W., Walker, R. W., and Warnatz, J., "Evaluated Kinetic Data for Combustion Modeling: Supplement II," Journal of Physical and Chemical Reference Data, Vol. 34, No. 3, 2005, pp. 757-1397. doi: $\underline{10.1063 / 1.1748524}$ 
This article has been cited by:

1. Te Zhao, Hong Ye, Lisong Zhang, Qilin Cai. 2017. Experimental Investigation on the Specific Heat of Carbonized Phenolic Resin-Based Ablative Materials. International Journal of Thermophysics 38:10. . [Crossref]

2. James B. Scoggins, Jason Rabinovitch, Benjamin Barros-Fernandez, Alexandre Martin, Jean Lachaud, Richard L. Jaffe, Nagi N. Mansour, Guillaume Blanquart, Thierry E. Magin. 2017. Thermodynamic properties of carbon-phenolic gas mixtures. Aerospace Science and Technology 66, 177-192. [Crossref]

3. Peter G. Cross, Iain D. Boyd. Reduced Reaction Mechanism for Rocket Nozzle Ablation Simulations . [Citation] [PDF] [PDF Plus]

4. Nicholas Martin, Jason M. Meyers, Douglas G. Fletcher, David Dang, Iain D. Boyd. Investigation of Pyrolyzing Ablators Using a Gas Injection Probe . [Citation] [PDF] [PDF Plus]

5. Alexandre Martin, Sean C. C. Bailey, Francesco Panerai, Raghava S. C. Davuluri, Huaibao Zhang, Alexander R. Vazsonyi, Zachary S. Lippay, Nagi N. Mansour, Jennifer A. Inman, Brett F. Bathel, Scott C. Splinter, Paul M. Danehy. 2016. Numerical and experimental analysis of spallation phenomena. CEAS Space Journal 8:4, 229-236. [Crossref]

6. Ali D. Omidy, Francesco Panerai, Jean R. Lachaud, Nagi N. Mansour, Alexandre Martin. 2016. Effects of Water Phase Change on the Material Response of Low-Density Carbon-Phenolic Ablators. Journal of Thermophysics and Heat Transfer 30:2, 473-478. [Citation] [Full Text] [PDF] [PDF Plus]

7. Alexandre Martin, Iain D. Boyd. 2015. Modeling of Heat Transfer Attenuation by Ablative Gases During the Stardust Reentry. Journal of Thermophysics and Heat Transfer 29:3, 450-466. [Abstract] [Full Text] [PDF] [PDF Plus]

8. David Smith, Todd R. White, Alexandre Martin. Comparisons of PICA In-depth Material Performance and Ablator Response Modeling from MEDLI Arc Jet Tests . [Citation] [PDF] [PDF Plus] 